\title{
Evolution and genetic diversity of Theileria
}

Thillaiamapalam Sivakumar, ${ }^{\mathrm{a}, \mathrm{b}}$, Kyoko Hayashida ${ }^{\mathrm{a}}$, Chihiro Sugimoto ${ }^{\mathrm{c}}$, Naoaki Yokoyama ${ }^{\mathrm{a}, *}$

${ }^{a}$ National Research Center for Protozoan Diseases, Obihiro University of Agriculture and Veterinary Medicine, Obihiro, Hokkaido, Japan.

${ }^{\mathrm{b}}$ Veterinary Research Institute, Peradeniya, Sri Lanka.

${ }^{\mathrm{c}}$ Division of Collaboration and Education, Research Center for Zoonosis Control, Hokkaido University, Sapporo, Hokkaido, Japan.

${ }^{*}$ Corresponding author (Naoaki Yokoyama):

National Research Center for Protozoan Diseases, Obihiro University of Agriculture and Veterinary Medicine, Inada-cho, Obihiro, Hokkaido 080-8555, Japan.

Tel.: +81-155-49-5649; Fax: 81-155-49-5643

E-mail: yokoyama@obihiro.ac.jp 


\section{Abstract}

Theileria parasites infect a wide range of domestic and wild ruminants worldwide, causing diseases with varying degrees of severity. A broad classification, based on the parasite's ability to transform the leukocytes of host animals, divides Theileria into two groups, consisting of transforming and non-transforming species. The evolution of transforming Theileria has been accompanied by drastic changes in its genetic makeup, such as acquisition or expansion of gene families, which are thought to play critical roles in the transformation of host cells. Genetic variation among Theileria parasites is sometimes linked with host specificity and virulence in the parasites. Immunity against Theileria parasites primarily involves cell-mediated immune responses in the host. Immunodominance and major histocompatibility complex class I phenotype-specificity result in a host immunity that is tightly focused and strain-specific. Immune escape in Theileria is facilitated by genetic diversity in its antigenic determinants, which potentially results in a loss of $\mathrm{T}$ cell receptor recognition in its host. In the recent past, several reviews have focused on genetic diversity in the transforming species, T. parva and T. annulata. In contrast, genetic diversity in $T$. orientalis, a benign non-transforming parasite, which occasionally causes disease outbreaks in cattle, has not been extensively examined. In this review, therefore, we provide an outline of the evolution of Theileria, which includes $T$. orientalis, and discuss the possible mechanisms generating genetic diversity among parasite populations. Additionally, we discuss the potential implications of a genetically diverse parasite population in the context of Theileria vaccine development.

Keywords: Evolution, genetic diversity, immunity, Theileria. 


\section{Introduction}

Theileria parasites infect a wide range of hosts, including domestic and wild ruminants, and often induce clinical disorders in the infected animals. Although several nonruminant animals are also described as being hosts for Theileria parasites, such as Theileria youngi in woodrat (Kjemtrup et al., 2001), T. annae in fox (Camacho et al., 2001), and T. equi in horse (Mehlhorn and Schein, 1998), these species are considered to have evolved prior to Theileria species of ruminants (Criado-Fornelio et al., 2003). Theileria parasites can be broadly categorized into two groups, consisting of host-cell transforming and nontransforming species. Traditionally, the following species have been described as transforming Theileria: T. parva, T. annulata, T. lestoquardi, and T. taurotragi (Dobbelaere and Küenzi, 2004; Sugimoto and Fujisaki, 2002). However, the recent studies added Theileria sp. (buffalo), a benign Theileria parasite in African buffaloes, to the list of transforming parasite species (Chaisi et al., 2011; Zweygarth et al., 2009). Several species of non-transforming parasites exist, including T. orientalis, T. mutans, T. velifera, and T. cervi. This classification is based on the parasite's ability to transform host leukocytes in a way that enables the infected cells to proliferate indefinitely along with the parasites occupying them. Non-transforming Theileria parasites do not induce this type of host-cell proliferation. Although the parasites in the latter category are considered to be relatively benign, disease outbreaks and economic losses related to the farm animals affected are not uncommon (Aparna et al., 2011; Eamens et al., 2013; McFadden et al., 2011). The taxonomy of the benign T. sergenti/buffeli/orientalis group is controversial. Arguments have been put forward both ways that these parasites should be classified as one species or as separate species within a group (Fujisaki et al., 1994; Gubbels et al., 2000a; Kakuda et al., 1998; Uilenberg et al., 1985). We have used the common taxonomic name, $T$. orientalis, throughout this review. 
T. parva and T. annulata are both known to infect cattle (Bos Taurus/B. indicus) and buffaloes (Syncerus caffer/Bubalus bubalis) (Bishop et al., 2004), while T. orientalis infects yaks (Bos grunniens) as well as cattle and buffaloes (B. bubalis) (Fujisaki et al., 1994; Yin et al., 2004). In addition, several Theileria species (T. lestoquardi, T. separata, T. uilenbergi, T. luwenshuni, T. capreoli, and T. ovis) have been reported to infect small ruminants (Ahmed et al., 2006). Wild ruminants, such as deer, antelope, and giraffe, are infected with several as yet unclassified Theileria parasites, some of which are highly pathogenic and often lead to death among these animals (Höfle et al., 2004; Nijhof et al., 2005; Oosthuizen et al., 2009).

The lifecycle of Theileria parasites in the ruminant host and tick vector has been reviewed (Bishop et al., 2004; Shaw and Tilney, 1992). Briefly, the lifecycle involves asexual reproduction of the blood-stage parasites in the host animal, and sexual reproduction of the parasites in a tick vector. The lifecycle in the vertebrate host begins with infection by sporozoites during blood-feeding of infected ticks. Thereafter, the sporozoites infect nucleated blood cells, where they may transform into schizonts. In the case of transforming Theileria, the infected cells (leukocytes) can multiply indefinitely in the host when they are harboring such parasites, and schizont-infected cells are often found in the circulating blood (Dobbelaere and Heussler, 1999). Subsequently, the merozoites released upon lysis of the infected leukocytes progress to infect host erythrocytes (RBCs) and then develop into piroplasms. Although enlarged cells containing structures suggestive of schizonts have been identified in the lymph nodes, spleen and liver of $T$. orientalis-infected cattle (Sato et al., 1993), the details of schizont development remain unclear in non-transforming Theileria (Sugimoto and Fujisaki, 2002). For T. annulata, further multiplication of the piroplasms (merogony) occurs in the RBCs, while it is limited in T. parva (Conrad et al., 1986). In nontransforming Theileria, merogony has been observed in RBCs (Kawamoto et al., 1990). Finally, when the ticks feed on an infected host, they acquire blood-stage Theileria parasites, 
including the gametes. The gametes undergo sexual reproduction in the midgut of the vector competent tick species, where genetic recombination occurs during meiosis (Katzer et al., 2006; Morzaria et al., 1993; Weir et al., 2007). Theileria parasites are trans-stadially transmitted by the tick vectors; therefore, the known transmission vectors are usually 2- or 3host tick species (Bishop et al., 2004).

Although a number of studies have described the evolution of piroplasmids (Babesia and Theileria), their findings have often differed from each other, with no single conclusion forthcoming (Criado-Fornelio et al., 2003; Lack et al., 2012). Contrasting timescales have been estimated by different researchers for the divergence time of the piroplasma, based on different genes and methodologies (Criado-Fornelio et al., 2003; Gou et al., 2013; Lack et al., 2012). In addition, one of the major controversies related to piroplasmid evolution is whether these parasites evolved first in vertebrate hosts or in ticks. Scientists are divided on this, and have based their conclusions on various assumptions and arguments (Criado-Fornelio et al., 2003; Schnittger et al., 2012).

Protozoan parasites are thought to have evolved genetic diversity to survive the immunologically unfavorable environments of their hosts. Genetic diversity often results in antigenic variation in parasites, thereby enabling them to escape the immune responses of their hosts (Deitsch et al., 2009). Recombination during sexual reproduction is probably a major mechanism underlying the genetic diversity of Theileria species (Henson et al., 2012; Katzer et al., 2006; Morzaria et al., 1993; Weir et al., 2007). Bioinformatic analyses have revealed genetic recombination to be a possible mechanism generating genetic diversity in genes such as the polymorphic immunodominant molecule (PIM) of T. parva and the $T$. annulata surface protein (TaSP) (Geysen et al., 2004; Schnittger et al., 2002). In addition to genetic recombination, mutations in the epitopes of $\mathrm{CD}^{+}$cytotoxic $\mathrm{T}$ lymphocyte (CTL) antigens were found to facilitate immune evasion in T. parva (Connelley et al., 2011). While 
the evolutionary acquisition of genetic diversity is beneficial to the long-term survival of the parasites, it often complicates the establishment of control measures against the diseases caused by them. Therefore, a thorough knowledge of genetic diversity in Theileria parasites is essential if we are to gain better understanding of these harmful organisms. In this review, we summarize the findings of past studies on the evolution and genetic diversity of T. parva, T. annulata, and $T$. orientalis. We also discuss the possible relationships between genetic diversity, host specificity, and virulence. 


\section{Evolution of Theileria: an overview}

Evolutionary studies are essential for understanding the biological behaviors of living things. Despite the economic significance of Theileria parasites, detailed studies have not been conducted to investigate their evolutionary processes. Therefore, in this review, we summarize the relevant findings of previous work and provide an outline of Theileria evolution.

\subsection{Early evolution of piroplasmids}

Studies on piroplasmid evolution have produced contrasting evolutionary time scales. Criado-Fornelio and co-workers (2003), in an 18S rRNA-based study, estimated that the ancestor of current-day piroplasmids originated 57 million years ago (mya). In contrast, Lack et al. (2012) estimated that the divergence time for piroplasmida was 17.11 mya although the study was based on $18 S$ rRNA sequences. The time difference was suggested to result from the different evolutionary models used for the phylogenetic analyses. A more recent study, which was based on cytochrome oxidase I, suggested that the divergence time of the piroplasmids might be 56.48 mya (Gou et al., 2013).

In addition to the controversial timescales for piroplasmid evolutionary history, whether the piroplasmids evolved first in vertebrate hosts or in ticks is a question that has prompted different responses from researchers (Criado-Fornelio et al., 2003; FlorinChristensen and Schnittger, 2009; Lack et al., 2012; Schnittger et al., 2012). Criado-Fornelio et al. (2003) provided a detailed scenario, linking the evolution of the piroplasmids with that of the host animals. Based on their hypothesis, piroplasmids fall into five groups: Archaeopiroplasmids, Prototheilerids, Theilerids, Babesids, and Ungulibabesids, based on 
their $18 S$ rRNA sequences (Fig. 1). Archaeopiroplasmids (B. rodhaini, B. felis, B. leo, B microti, and T. annae) are considered to be the ancestors of the piroplasmids (Criado-Fornelio et al., 2003). Recent genomic data for several piroplasmids also support this view. The variant erythrocyte surface antigen (VESA) gene family, which includes about 150 genes in $B$. bovis, contains three genes in $B$. microti that have not been detected in Theileria parasites (Brayton et al., 2007; Cornillot et al., 2012). Additionally, the gene families Tpr and Tar, which are composed of several tandemly arranged or dispersed open reading frames characterized by repeated elements (Baylis et al., 1991), contain 39 and 83 genes in T. parva and T. annulata, respectively, while similar gene families in B. microti, B. bovis, and T. orientalis have only four to five genes in each of their genomes (Cornillot et al., 2012; Gardner et al., 2005; Hayashida et al., 2012; Pain et al., 2005). These findings possibly provide further support for the Archaeopiroplasmids as ancestors, because the multicopy genes, which have substantially expanded over evolutionary time in some Babesia and Theileria parasite lineages, have limited copy numbers in the B. microti genome.

Criado-Fornelio et al. (2003) have suggested that the initial stages of piroplasmid evolution could have occurred in a vertebrate host, possibly a rodent or carnivore. Transovarial transmission in tick vectors is a unique feature of large Babesia parasites (Homer et al., 2000), such as B. bovis, B. bigemina, B. divergens, B. caballi, and B. canis, but they have evolved recently (Allsopp et al., 1994). Because Archaeopiroplasmids lack the ability to undergo the transovarial transmission in ticks, maintenance of these ancestors among the ticks would have been unlikely. This assumption rules out ticks as the initial hosts in which the early evolution of the piroplasmids might have occurred (Allsopp et al., 1994; Criado-Fornelio et al., 2003). Additionally, it is noteworthy that Nephromyces parasites of Molgula species (sea grapes) and Cardiosporidium cionae of ascidian Ciona intestinalis, which share a common ancestor with the piroplasmids, are not known to be vector 
transmitted (Ciancio et al., 2008; Saffo et al., 2010). If the piroplasmids initially evolved in vertebrate hosts, the next question is obvious: how did the ancestral piroplasmids complete their lifecycles? There are two possible transmission patterns. One possibility is that the parasites might have been vertically transmitted from their hosts to their offspring; this transmission pattern has been reported in B. microti and B. gibsoni (Joseph et al., 2012; Fukumoto et al., 2005), which have evolved early (Archeopiroplasmids and Prototheilerids, respectively, in Fig. 1). The second possibility is transmission via fighting- or predationrelated physical injuries, which may have been commonplace among the rodent and carnivorous hosts. It is noteworthy that $B$. gibsoni can be directly transmitted among fighting dogs (Jefferies et al., 2007). In contrast, another group of researchers have argued that the piroplasms might have evolved in ticks initially by citing evolutionary time scales that place the piroplasmids and ticks ahead of mammals (Florin-Christensen, and Schnittger, 2009; Schnittger et al., 2012). However, as controversy related to the divergence time continues, it remains difficult to describe piroplasmid evolution using only the time scales of the radiations.

Even if the initial evolutionary processes were not dependent on the ticks, this does not mean that these Acari did not influence piroplasmid evolution. Initially, the multi-host ticks are likely to have transmitted the parasites, as the piroplasmid ancestors did not have the ability to undergo transovarial transmission in ticks. The authors of a previous study suggested that the piroplasmid ancestors may have been able to infect nucleated blood cells (Allsopp et al., 1994), as observed in B. microti (Mehlhorn et al., 1986), an ability that evolved prior to Babesids and Ungulibabesids, which usually only infect RBCs. While the ancient piroplasmids were evolving in different host and tick species over a long time period, a section of the parasite population might have lost their ability to infect nucleated blood cells but gained the ability to undergo transovarial transmission in similarly adapted tick species, 
and evolved into true Babesia species (Babesids and Ungulibabesids in Fig. 1) (Allsopp et al., 1994). In contrast, parasites that had retained the ability to infect nucleated blood cells continued to evolve as true Theileria parasites of ruminants (Allsopp et al., 1994; Schnittger et al., 2012).

\subsection{Transforming Theileria: a breakthrough in evolution}

A major breakthrough in the evolution of Theileria relates to its ability to form leukocyte-transforming parasites. Both host and tick vectors might have influenced the evolution of the transforming types of Theileria parasites (Criado-Fornelio et al., 2003). Buffaloes are considered to be the primordial hosts for transforming Theileria species (Bishop et al., 2004). It is commonly believed that T. parva evolved primarily in African buffaloes (Syncerus caffer), while T. annulata originated in water buffaloes (Bubalus bubalis) (McKeever, 2009). The evolution of transforming Theileria could have been heavily influenced by the immune response in buffaloes (McKeever, 2009). Consistent with this, the genes encoding several key antigens of $T$. parva, such as the p67 and some of the CTL antigens, are more diverse among field isolates from African buffaloes than those from cattle

(Nene et al., 1999; Pelle et al., 2011), suggesting that the immune engagement of T. parva is greater in buffaloes than cattle (McKeever, 2009). In addition to host immunity, tick vectors may also have influenced the evolution of transforming Theileria, as these transforming Theileria species are transmitted only by specific species of ticks (Bishop et al., 2004). Therefore, it is no coincidence that the geographical distributions of these pathogens are correlated with those of their tick vectors (Criado-Fornelio et al., 2003).

According to the phylogeny based on $18 S$ rRNA sequences (Fig. 1), transforming $T$. parva, T. annulata, T. lestoquardi, and T. taurotragi species are located in the same cluster, 
thereby having a common ancestor (Allsopp et al., 1994; Lack et al., 2012); a similar pattern was observed in a phylogram constructed from major piroplasm surface protein (MPSP) gene sequences (Gubbels et al., 2000a). Phylogenetic analysis of p67 and its orthologous gene sequences yielded almost similar results to those of $18 S$ rRNA and MPSP (Fig. 2). Despite having a common ancestor, the members of transforming Theileria differ from each other in their host specificity and pathogenicity (Mans et al., 2011b). Therefore, the common ancestor of transforming parasites could have independently evolved into different Theileria species. For instance, T. parva and T. annulata independently evolved in African and water buffaloes, respectively. The different target lymphocytes for T. parva, which transforms B and $\mathrm{T}$ lymphocytes, and $T$. annulata, which transforms $\mathrm{B}$ lymphocytes and monocytes/macrophages, might explain this assumption (Dobbelaere and Heussler, 1999).

The availability of whole genome sequences for transforming ( $T$. parva and $T$. annulata) and non-transforming (T. orientalis) parasites allows us to discuss the possible genetic changes associated with the evolution of the former parasite category (Gardner et al., 2005; Pain et al., 2005; Hayashida et al., 2012). The evolution of transforming Theileria is associated with the acquisition or expansion of specific gene families that are potentially involved in host-cell modifications. Subtelomeric variable secreted proteins, otherwise known as subtelomere-encoded variable secreted proteins (SVSPs), are encoded by a large multicopy gene family positioned at the chromosome ends in T. parva and T. annulata (Schmuckli-Maurer et al., 2009). SVSPs, which are secreted into the cytoplasm of infected cells, may be involved in phenotypic changes in the host cells or parasite immune evasion (Schmuckli-Maurer et al., 2009). Interestingly, this gene family is absent in non-transforming T. orientalis (Hayashida et al., 2012), suggesting that the SVSPs are associated with the transformation process. The partially conserved synteny between the SVSP genes of T. parva and $T$. annulata suggests that the evolution of this gene family started before the 
diversification of these species (Weir et al., 2010). Therefore, detection of SVSP-like genes in T. lestoquardi and T. taurotragi provides supportive evidence that transforming Theileria species probably originated from a common ancestor.

A tandemly clustered large gene family, which encodes TpshHN or TashAT, was detected in T. parva or T. annulata, respectively (Swan et al., 1999, 2001). In marked contrast to transforming Theileria, the related gene in $T$. orientalis was detected as a singlecopy ortholog, suggesting that expansion of the gene family occurred after speciation (Hayashida et al., 2012). Weir et al. (2009) found that the orthologous internal genes of $T$. parva TpshHN and T. annulata TashAT families are located in separate clades in the phylogram, while the genes flanking the internal clusters of the TpshHN and TashAT families formed common clades. Based on these findings, the authors proposed that the gene families had expanded independently from a common ancestor of $T$. parva and $T$. annulata. Additionally, Tpr and Tar copy numbers are significantly higher in T. parva and T. annulata than in $T$. orientalis, suggesting that these gene families have also expanded only in the transforming parasites (Hayashida et al., 2012). However, the recent genome project for $T$. equi found that the Tar-like gene family had 109 members (Kappmeyer et al., 2012). Therefore, it would be difficult to conclude that the Tpr and Tar gene expansions are related to the evolution of the host-cell transforming behavior of Theileria.

CTL responses play a significant role in effective host immunity against T. parva infection (McKeever et al., 1994; Taracha et al., 1995a). Tp9 and Ta9, which encode antigens that were identified as one of the CTL determinants in T. parva and T. annulata, respectively, are the members of orthologous gene families in these parasite species (Katzer et al., 2006; MacHugh et al., 2011). In contrast, only a single gene, which shares weak homology to Tp9 and Ta9, was found in the T. orientalis genome (Hayashida et al., 2012).

Thus, it seems that during the course of evolution, several key antigens in 
transforming Theileria have undergone gene duplication, which may have altered their function and contributed to the unique biology of these parasites. In summary, transforming Theileria parasites have evolved with radical genomic changes, allowing them to find a safe haven where they could survive, multiply, and ensure their continuous circulation within their host animals.

\subsection{T. parva: cattle vs buffaloes}

T. parva of cattle is considered to originate from African buffaloes. However, there are marked differences in the T. parva populations between cattle and African buffaloes. $T$. parva derived from cattle and buffaloes are sometimes referred as $T$. parva parva and $T$. parva lawrencei, respectively; these cause East Coast fever (ECF) and Corridor disease in cattle (Uilenberg, 1999). Several genes that encode antigenic determinants in T. parva from buffaloes differ from those in cattle. For example, T. parva p67 gene sequences in African buffaloes clearly differ from those of cattle-derived T. parva isolates (Nene et al., 1996; Pelle et al., 2011). In addition, studies conducted in cattle previously in contact with African buffaloes have shown the presence of buffalo-derived Tp1 and Tp2 gene sequences, which are two CTL antigen-encoding genes in T. parva, in the cattle populations (Pelle et al., 2011). Although a subset of the buffalo-derived T. parva population (T. parva lawrencei) was able to infect cattle and cause heavy mortality among them (Corridor disease), the parasite was not transmitted to other cattle (Uilenberg, 1999). Nonetheless, these parasite lineages were associated with the acute death of infected cattle despite the cattle developing only low parasitemias (Uilenberg, 1999). However, if the buffalo-derived parasites are maintained at the carrier stage in cattle, the potential exists for them to be transmitted among cattle populations by ticks (Uilenberg, 1981). In brief, while the T. parva maintained in African 
buffaloes evolved a long time ago, domestic cattle were introduced relatively recently, perhaps in the region of around 6,000 years ago (Freeman et al., 2006). When cattle populations were introduced, some T. parva of buffalo origin may have gained the ability to infect cattle through ticks. Subsequently, a subset of these buffalo-derived T. parva (T. parva parva) evolved adaptions to cattle. T. parva parva, which is transmitted among the cattle populations by ticks, causes ECF in cattle (Pelle et al., 2011). Adaption of buffalo-derived parasites to cattle is a continuous process, and one that is believed to occur when both host animal species are maintained in close proximity (Uilenberg, 1981). Although T. parva of cattle originated from African buffaloes, the parasites in both of the host animals differ from each other, especially in terms of their transmission characteristics and genetic diversity. This conclusion is also supported by recent findings from the whole genome sequences of T. parva isolates derived from cattle and African buffaloes, which show that recombination is unlikely between the cattle- and buffalo-derived parasites (Hayashida et al., 2013).

In African buffaloes, in addition to T. parva, two other Theileria species, Theileria sp. (buffalo) and Theileria sp. (bougasvlei) were reported (Mans et al., 2011a). Although they are closely related to T. parva, researchers found that monoclonal antibody profiles were different between T. parva and Theileria sp. (buffalo) and that the small subunit ribosomal rRNA probes can distinguish them (Allsopp et al., 1993; Conrad et al., 1987). Phylogenetic analysis based on $18 S$ rRNA gene sequences suggested the existence of $T$. parva and 2 other Theileria species in African buffaloes (Chaisi et al., 2011). Mans et al. (2011a,b) provided further evidences to suggest that T. parva, Theileria sp. (buffalo), and Theileria sp. (bougasvlei) are three separate species based on S5 ribosomal gene and V4 hyper-variable region of $18 S$ rRNA sequences. These observations were strongly supported by the cytochrome oxidase gene-based phylogeny in which T. parva, Theileria sp. (buffalo), and Theileria sp. (bougasvlei) had been separated into different clades with high bootstrap values 
(Pienaar et al., 2014). T. parva in African buffaloes can be transmitted by ticks to cattle where the parasite may induce clinically significant corridor disease (Uilenberg, 1999), while Theileria sp. (buffalo) and Theileria sp. (bougasvlei) are considered to be benign and not known to infect cattle (Mans et al., 2011a). Therefore, the recently developed sensitive realtime hybridization PCR method that can discriminate T. parva, Theileria sp. (buffalo), and Theileria sp. (bougasvlei) might be a useful technique for the differential diagnosis of $T$. parva in African buffaloes (Pienaar et al., 2011). Theileria sp. (buffalo) is a transforming Theileria species as the parasite can be cultured in vitro in mononuclear cells from buffaloes (Zweygarth et al., 2009). Comparative genomic studies are now a priority to understand the evolutionary relationship between T. parva and these yet unnamed Theileria species in African buffaloes.

\subsection{Evolution of non-transforming Theileria}

Non-transforming Theileria species evolved independently from those of transforming Theileria. Based on the phylogeny inferred from the $18 S$ rRNA sequences (Fig. 1) (Lack et al., 2012), it is obvious that multiple host species could have been involved in the evolution of non-transforming Theileria. In addition, the tick vectors do not tightly regulate transmissions of these parasites, because parasite species-specific transmission patterns are not observed in different tick species (Gou et al., 2013). Perhaps, during their evolutionary processing, the benign Theileria parasites passed through several types of host family, such as Giraffidae, Cervidae, Capridae, and Bovidae, establishing local populations among them. Therefore, these parasite species could have spread throughout the world in different species of wild and domestic ruminants (Criado-Fornelio et al., 2003). T. orientalis found in different host animals, such as cattle, buffaloes, and yaks, is one such parasite species. 
In the phylogram based on MPSP sequences (Fig. 3), cattle and yak-derived $T$. orientalis sequences form the ancestral clade (Type 6 in Fig. 3) (Gubbels et al., 2000a), suggesting that the initial evolution of this parasite species could have occurred in Bos species rather than water buffaloes. However, further evolution of T. orientalis into a wide range of genotypes would have been possible only after the involvement of water buffaloes, as inferred from the MPSP gene-based phylogeny. Survival of the non-transforming Theileria species might have been much easier than it was for the transforming species, as the former group can be transmitted by several species of tick vectors to different host animals (Fujisaki, 1992).

\section{Genetic diversity: a Theileria survival strategy with implications for its control}

Genetic diversity is considered to be the raw material for the evolution of living things (Whitehead and Crawford, 2006). Genetic variation within populations of Theileria is known to be one of the survival strategies used by these pathogens. The sophisticated mechanisms of genetic and epigenetic diversity, like the cases of VESA1 and variable surface glycoprotein (VSG) gene families of B. bovis and Trypanosoma brucei, respectively (AlKhedery and Allred, 2006; Hoeijmakers et al., 1980; Myler et al., 1984), are not common in Theileria species. Perhaps the immune pressure against these parasites is diluted by phenotypic differences in the major histocompatibility complex (MHC) of the host, as host immunity against Theileria is largely cell-mediated (McKeever et al., 1994). However, significant genetic variation is observed among parasite field isolates, and these differences are considered to result mainly from recombination in the tick vectors (Katzer et al., 2006; Morzaria et al., 1993; Weir et al., 2007) although other mechanisms, such as genetic drift (Weir et al., 2010) and mutations (Bishop et al., 1997), can also contribute to genetic 
variation. Genetic variation among the coding sequences of some vaccine candidate antigens is a major constraint for the development of subunit vaccines. Therefore, vaccine control strategies against Theileria parasites should preferably be designed in light of their genetic diversity. Evidence for the influence of host immunity on parasite genetic diversity has been reviewed in the recent past (McKeever et al., 2009). In the present review, therefore, we summarize recent progress in research on these important aspects of genetic diversity in Theileria parasites.

\subsection{Mechanisms underlying genetic diversity in Theileria}

Theileria parasites use several mechanisms to generate genetically diverse populations, and recombination can be considered a primary underlying mechanism. Genetic recombination is the exchange of genetic material between two homologous DNA sequences, and is thought to be an important mechanism leading to genetic diversity within a species population (Deitsch et al., 2009). Recombination during sexual reproduction is seen in several apicomplexan parasites, such as Plasmodium falciparum (Conway et al., 1999), Cryptosporidium parvum (Feng et al., 2002), and Toxoplasma gondii (Minot et al., 2012). Genetic recombination also occurs in populations of T. parva and T. annulata (Henson et al., 2012; Katzer et al., 2006; Weir et al., 2007). Recombination between two different T. parva stocks was demonstrated by analyzing parasite progenies derived from ticks that fed on cattle infected with two different stocks of the parasite (Henson et al., 2012; Katzer et al., 2011; Morzaria et al., 1993). A recently estimated genome-wide recombination rate for T. parva (Katzer et al., 2011) suggested that this parasite has a higher effective number of recombination events than those of several other protozoan species (Jiang et al., 2011; Khan et al., 2005; Martinelli et al., 2005; Sibley et al., 1992; Su et al., 1999; Tanriverdi et al., 2007; 
Walker-Jonah et al., 1992) (Table 1).

Several studies that have analyzed genetic diversity in individual genes or gene families have also provided supportive evidence for recombination in Theileria species. TaSP, which is a surface antigen of T. annulata, is expressed in both sporozoites and schizonts (Schnittger et al., 2002). With the exception of the terminal conserved regions, the TaSP gene sequences are highly diverse. Intragenic recombination, which results in a mosaic pattern of genetic diversity, and substitutions by mutation in TaSP were suggested to be the underlying mechanisms of diversity in this gene (Schnittger et al., 2002). Genetic diversity has been extensively studied in Tams-1, a T. annulata merozoite antigen (Gubbels et al., 2000b, 2001; Katzer et al., 1998). The mosaic pattern of genetic diversity observed among Tams-1 gene sequences from different isolates is also likely to be generated by intragenic recombination, by which the variable domains are exchanged (Gubbels et al., 2000b). Although a homologous antigen, called the $32 \mathrm{kDa}$ antigen (Tpms-1), has been detected in T. parva, its full pattern of genetic diversity has not been established (Skilton et al., 2000). In addition to the genetic diversity generated by intragenic recombination among single-copy gene sequences, this mechanism has also been implicated in the diversity observed among members of the multicopy gene family SVSP (Schmuckli-Maurer et al., 2009). Interestingly, the mRNA expression profiles of selected T. parva SVSPs differed between the individual genotypes, with a particular SVSP expressed only in a minor percentage of the parasites (Schmuckli-Maurer et al., 2009). Weir et al. (2010) observed that the sequences of $T$. annulata SVSP gene family members were also polymorphic between isolates, with the underlying mechanism generating such diversity suggested to be recombination.

T. parva PIM, which is a homologous antigen to T. annulata TaSP, is also expressed in the sporozoite and schizont stages (Toye et al., 1991). Strong humoral immunity against the PIM is often observed in infected cattle, and therefore this antigen is a target for the 
development of serodiagnostic assays (Katende et al., 1998). Similar to TaSP, PIM gene sequences are characterized by conserved terminal and diverse central regions (Toye et al., 1995). However, the major mechanism behind this type of polymorphism is thought to be gene conversion (Geysen et al., 2004), a mechanism by which a fragment of genomic DNA is nonreciprocally copied onto a homologous fragment (Duret and Galtier, 2009; Galtier et al., 2001). A recent genome project identified a PIM/TaSP orthologous gene in $T$. orientalis (TOT_040000883) (Hayashida et al., 2012). Comparative studies exploring the mechanism of genetic diversity in PIM/TaSP and orthologous genes in other Theileria species are now required.

Gene isolation, as characterized by restricted gene flow among populations (Seehausen et al., 2014), and genetic drift, as defined by random changes in allelic frequency due to chance (Charlesworth, 2009), can also influence genetic diversity in Theileria species at a population level. Gene isolation and genetic drift often limit genetic diversity or genotypic distribution within a finite population (Livingstone, 1972). TashHN and SuAT1 genes, which are members of the $T$. annulata TashAT gene family, were found to be geographically substructured when Turkish and Tunisian isolates were phylogenetically analyzed (Weir et al., 2010). Furthermore, the Tunisian sequences were found to be highly conserved. Thus, it was suggested that genetic variation in these two T. annulata genes was a result of gene isolation and genetic drift (Weir et al., 2010).

Although the ultimate source of genetic diversity is mutation (Frankham et al., 1980), the extent of its direct influence on genetic diversity in Theileria is not very clear. However, mutations can potentially make significant contributions to genetic diversity in Theileria parasites under certain circumstances. Each member of the T. parva multicopy gene family Tpr includes one, two, or three of the repeat elements Tpr3, Tpr2, and Tpr1 (Baylis et al., 1991). A repeat element is usually conserved among genes of a Tpr family in a particular 
genome. For example, copies of Tpr1 and Tpr2 within the T. parva Muguga genome showed that the Tpr1 sequences were $90 \%$ similar, while the Tpr2 sequences shared $97 \%$ similarity (Bishop et al., 1997). However, the sequence similarity of Tpr1 or Tpr2 between the Muguga sequences and other T. parva isolates was found to be only 75\% (Bishop et al., 1997). The conserved nature of the repeated elements in Tpr within a particular genome was thought to be caused by the rapid dissemination of mutations occurring within the individual gene copies through various mechanisms, such as unequal crossing over and gene conversion, assisted by their tandem arrangement (Bishop et al., 1997). Even so, although a mutation may not always result in pronounced genetic diversity, it could play an important role in Theileria survival. For example, mutations in CTL antigen epitopes were found to facilitate immune evasion in T. parva and T. annulata (Connelley et al., 2011; MacHugh et al., 2011) (see section 3.2).

The T. parva sporozoite-specific antigen p67 is highly immunogenic and induces neutralizing antibodies (Musoke et al., 1992). Interestingly, p67 is highly conserved among cattle-derived isolates, while in buffaloes it is not only genetically diverse, but also diverged from cattle homologs (Nene et al., 1996). Its homologous antigen in T. annulata (called SPAG-1) shows similar immunogenic characteristics to p67 (Boulter et al., 1994), but several allelic forms of SPAG-1 were found in cattle populations (Katzer et al., 1994). A recent study showed that p67 is in a genomic region with low recombination activity (Katzer et al., 2011). However, this observation does not rule out possible recombination between $p 67$ alleles, as detailed bioinformatic analyses have not been carried out on this gene. Nevertheless, the exact mechanism underlying genetic variation in p67 and SPAG-1 is not known. The recently completed genome project identified an orthologous gene in T. orientalis (Hayashida et al., 2012). Although its pattern of genetic diversity has not been determined, it is likely that this gene is also diverse among different genotypes of the parasites, because buffaloes play an 
important role in T. orientalis evolution (Altangerel et al., 2011b) as is the case for T. parva.

The MPSP gene of T. orientalis, which is considered orthologous to T. parva p32 and T. annulata Tams-1 genes (Hayashida et al., 2012), exhibits a different type of genetic diversity. Unlike T. annulata Tams-1, the MPSP gene sequences obtained from geographically different isolates cluster into limited numbers of clades in the phylogenetic tree (Khukhuu et al., 2011). Although four major genotypes were initially described based on a limited number of MPSP gene sequences (Kakuda et al., 1998; Sarataphan et al., 1999), analyses of a large number of the sequences showed that there are at least 11 genotypes, which include types 1-8, N1, N2, and N3 (Jeong et al., 2010; Khukhuu et al., 2011; Kim et al., 1998). These gene sequences share low sequence identities among the genotypes (Khukhuu et al., 2011), while the sequence identities within each clade are high (Altangerel et al., 2011a; Kim et al., 1998). Therefore, recombination between the different MPSP genotypes seems unlikely. We believe that the ongoing accumulation of point mutations and recombination within the MPSP genotypes could eventually lead to the formation of a novel allele.

In summary, several mechanisms, including recombination, isolation, genetic drift, and mutation, maintain genetic diversity in Theileria parasites. A thorough knowledge of the pattern and underlying mechanism of genetic diversity is essential to assess the possible limitations for using an effective polymorphic antigen-based subunit vaccine.

\subsection{Immunity-mediated genetic diversity}

The primary immune response against the schizont stages of Theileria parasites is thought to be cell-mediated, but the immunity is potentially strain-specific (McKeever et al., 1999). Early studies have suggested that a combination of several strains is essential for 
successful immunization with a live Theileria vaccine (Uilenberg, 1999). The effect that genetic diversity in $T$. parva and $T$. annulata has on host immunity has recently been reviewed. In this section, therefore, we have focused on recent developments in this area.

Several recent studies have examined genetic diversity in CTL antigens. Among the CTL determinants in T. parva, higher genetic diversity is observed in Tp1 and Tp2 variants than in other such antigens (MacHugh et al., 2009; McKeever, 2009). When these gene sequences were analyzed, high $\mathrm{dN} / \mathrm{dS}$ values (i.e., the ratio between the number of nonsynonymous substitutions per nonsynonymous site and number of synonymous substitutions per synonymous site) were observed (Pelle et al., 2011). However, positive selection acting on the T cell epitopes in the CTL antigens was not detected (Pelle et al., 2011). A later study, which analyzed the effect of amino acid substitutions in different locations of the Tp2 epitope on $\mathrm{T}$ cell receptor (TCR) recognition, found that amino acid substitution at the $3^{\text {rd }}$ or $6^{\text {th }}$ positions of the Tp2 $49-59$ epitope did not affect TCR recognition, and that the amino acid residues in these positions were conserved among several natural variants of this epitope (Connelley et al., 2011). Interestingly, the amino acid substitutions in natural variants of $\mathrm{Tp} 2_{49-59}$ preferentially occurred in positions that may be critical for the variants to escape from host cell-mediated immunity (Connelley et al., 2011). Recently, several CTL antigens have also been described in T. annulata. In particular, extensive genetic diversity was observed in the Ta9 gene (MacHugh et al., 2011). The amino acid substitutions in the $\mathrm{Ta}_{40-49}$ epitope resulted in loss of or differential recognition by $\mathrm{CD}^{+} \mathrm{T}$ cell clones (MacHugh et al., 2011). These findings indicate that genetic diversity in CTL epitopes could have been driven by cell-mediated immunity in host animals. However, immune pressure on the CTL antigens would be diluted by the phenotypic variations in host MHC molecules (McKeever, 2009). Therefore, the currently observed variations in the amino acid residues essential for MHC binding and TCR recognition may be influenced by the dominant MHC 
class I haplotypes of the host animals (McKeever, 2009).

For T. orientalis, the published information allows us to use the MPSP gene to focus on host immunity-mediated selection of this parasite. MPSP is known to include determinants for humoral and cellular immunity (Onuma et al., 1998; Kakuda et al., 2001). This antigen has also been considered as a vaccine candidate against theileriosis caused by $T$. orientalis (Onuma et al., 1998). Two CD4 ${ }^{+} \mathrm{T}$ cell epitopes were mapped in MPSP, and amino acid substitutions were found in those epitopes among field variants (Kakuda et al., 2001). However, further studies are essential to confirm whether the amino acid substitutions observed among these epitopes facilitate immune escape.

It is becoming clear that host immunity plays a key role in creating genetic diversity in Theileria species. While facilitating the survival of the parasite population, such immunitymediated genetic variation highlights the difficulties faced by immune control methodologies targeting Theileria parasites.

\subsection{Genetic diversity: a stumbling block for the development of subunit vaccines?}

Although several studies have been undertaken in the past to evaluate the potential of recombinant subunit vaccines against Theileria parasites (Boulter et al., 1995, 1999; Honda et al., 1998; Morzaria et al., 2000; Musoke et al. 1992; Onuma et al., 1998), no such vaccines are currently available for routine use. T. parva p67 is one of the most extensively investigated vaccine candidates. Musoke et al. (1992) showed that immunization with recombinant p67 protected $70 \%$ of the infected animals from severe disease. The conserved nature of the $p 67$ gene among cattle-derived T. parva parasites highlights the potential use of p67 as a subunit vaccine against ECF (Nene et al., 1996). In contrast, out of five epitopes recognized by a set of sporozoite-neutralizing monoclonal antibodies, absolute conservation 
was observed only for a single epitope among the p67 sequences sourced from the buffaloderived parasites (Nene et al., 1999, 1996). In addition, a recent study showed that genetic diversity in $p 67$ was higher than that expected in buffalo-derived parasite populations in South Africa (Sibeko et al., 2010). The homologous p67 antigen of T. annulata, SPAG-1, has also been evaluated for its potential as a vaccine (Boulter et al., 1998, 1999). SPAG-1 was able to reduce the parasitemias of cattle infected with $T$. annulata, while increasing the prepatent and incubation periods of infection and the survival rates among the immunized cattle (Boulter et al., 1999). Neutralization-sensitive epitopes have been identified in the Cterminal of SPAG-1, which shares 57\% similarity with that of p67 (Knight et al., 1996). Although the SPAG-1 gene is genetically diverse among field isolates, antibody responses against its epitopes are largely conserved (Williamson et al., 1989). Nevertheless, SPAG-1 and p67 were found to induce cross-species protection (Hall et al., 2000). Therefore, it is reasonable to speculate that genetic diversity in p67 and SPAG-1 may not constrain the use of these antigens as vaccines. These conserved immune responses may also imply that the effects of p67-induced host immunity on the parasites would be diluted at the population level because of variations in the MHC class II alleles of the host (Ballingall et al., 2004).

In addition to the antigens that are involved in host humoral immunity, those associated with cell-mediated immunity are promising vaccine candidates. One of the major obstacles in using CTL antigens for immunization is that the CTL responses they induce may be parasite strain-specific because of differences in the MHC class I haplotypes of the host animals (Goddeeris et al., 1990). Seven candidate antigens, Tp1, Tp2, Tp4, Tp5, Tp7, Tp8, and Tp9, have been identified in T. parva as CTL antigens (Graham et al., 2006; Katzer et al., 2006). Subsequently, the CTL epitopes in these antigens and their respective MHC restriction elements were determined (Graham et al., 2008). However, the CTL responses were directed toward a single CTL determinant, based on the host MHC class I haplotypes (MacHugh et al., 
2009). In brief, CTLs collected from T. parva-immunized cattle bearing A10 and A18 MHC class I haplotypes were shown to preferentially react with either Tp1 or Tp2, but not with other CTL antigens (MacHugh et al., 2009), confirming a previous suggestion that the CTL response might be characterized by immunodominance (Taracha et al., 1995b). MacHugh et al. (2009) also observed that Tp1 and Tp2 epitopes in natural variants were polymorphic, and that the Tp2 epitope variants resulted in differential recognition by the CTLs. In agreement with these findings, the loss of TCR recognition caused by CTL epitope diversity in Tp2 was found to be associated with immune escape (Connelley et al., 2011). In contrast, the CTLs collected from vaccinated cattle reacted with a Tp1 epitope $\left(\mathrm{Tp} 1_{214-224}\right)$ from different strains, suggesting that the genetic variations in this epitope may not result in altered immune responses (Steinaa et al., 2012). However, variation in the Tp1 epitope is limited only to its last two residues among natural variants that have been identified thus far (MacHugh et al., 2009). Additionally, the important amino acid residues for TCR recognition in the Tp1 epitope have not been defined yet. Therefore, the findings of these studies may not be conclusive as yet.

Similar to T. parva, primary immunity against T. annulata is cell-mediated. The involvement of $\mathrm{CD}^{+} \mathrm{T}$ cells and CTLs in host immune control of this parasite has been suggested (Preston et al., 1999). Analyses of the immune responses to T. annulata found that CTL responses were strain-specific, characterized by immunodominance, and determined by host MHC class I haplotypes (MacHugh et al., 2008, 2011). Ta9 is a CTL antigen of T. annulata, and its sequencing analysis showed that the CTL epitopes in the Ta9 variants were polymorphic and that the genetic diversity resulted in different recognition patterns in the CTLs (MacHugh et al., 2011). Although a single gene with weak homology to Tp9/Ta9 was recently reported in T. orientalis (Hayashida et al., 2012), further studies are needed to determine its role in CTL response and to define the genetic diversity of its potential epitopes. 
Nevertheless, it is clear that immune responses against T. parva and T. annulata are tightly focused and based on MHC-I haplotype recognition of certain CTL determinants creating immunodominance together with genetic variation in CTL epitopes.

T. orientalis MPSP is a vaccine candidate antigen against infection with this parasite species (Onuma et al., 1998). Despite high antibody titers against MPSP in persistently infected cattle, recurrent of parasitemia is often observed, suggesting that host humoral immunity against MPSP is insufficient to completely control the infection (Onuma et al., 1998). Furthermore, antibody response against MPSP can be type-specific (Iwasaki et al., 1998; Yokoyama et al., 2012). In MPSP, two CD4 ${ }^{+} \mathrm{T}$ cell epitopes were identified using T cells collected from Holstein cattle pre-immunized with recombinant MPSP (Kakuda et al., 2001). However, genetic diversity in the epitopes was evident when the epitopes in several MPSP-types were analyzed (Kakuda et al., 2001). Even so, while these epitopes were able to induce production of interferon- $\gamma(\mathrm{IFN}-\gamma)$ in the $\mathrm{T}$ cells collected from the $T$. orientalisinfected Holstein cattle, T cells from Angus and Japanese Black cattle did not respond fully to epitope stimulation (Yamaguchi et al., 2010). The reason for these observations was suggested to be related to differences in the MHC class II haplotypes of the cattle. Therefore, genetic diversity of potential $\mathrm{CD}^{+} \mathrm{T}$ cell epitopes in MPSP and variation among MHC haplotypes in different cattle breeds may complicate the development of an MPSP-based subunit vaccine against $T$. orientalis.

Despite several decades of research aimed at developing recombinant vaccines against Theileria parasites, such vaccines are still unavailable. In addition to MHC haplotype variation, genetic diversity in Theileria parasites constrains the development of subunit vaccines. Attempts to develop subunit vaccines against Theileria species will become fruitful only if the genetic diversity in parasite populations and the variation among MHC haplotypes could be orchestrated in a way that would cover most of the diversity in the parasite and host 
populations.

3.4. Relationships between genetic diversity, host specificity and virulence in Theileria parasites

How virulent a Theileria species is generally depends on the host species it infects. Buffaloes usually remain asymptomatic when infected with Theileria (Mckeever, 2009). In contrast, these parasites cause clinical disease in cattle with varying degrees of severity (Eamens et al., 2013; Irvin and Mwamachi, 1983). Although T. parva derived from cattle (T. parva parva) and buffalo (T. parva lawrencei) differ genetically from each other (Hayashida et al., 2013; Nene et al., 1999; Pelle et al., 2011), they cause more or less equally severe diseases in cattle (ECF and Corridor disease, respectively) (Nambota et al., 1994). However, low virulence, which affords the parasite greater immune engagement with its host, is thought to account for the high genetic diversity of T. parva in buffaloes, whereas, in cattle, parasites that cause severe disease leading to acute death have a reduced chance of immune-mediated selection acting on them (McKeever, 2009). Therefore, it appears that parasite virulence influences genetic diversity in T. parva, not the other way around. In addition, the evolution of T. parva in African buffaloes began well before the parasite evolved adaptions to cattle, and therefore, this could also be a reason why the genetic diversity of $T$. parva is greater in buffaloes than in cattle (Pelle et al., 2011).

In contrast, evidence is mounting on the genotype-dependent virulence of $T$. orientalis in cattle. A recent study in Australia found that MPSP-type 2 was involved in several clinical cases in the infected cattle (Eamens et al., 2013). Although Aparna et al. (2011) detected the MPSP-type 7 in clinical theileriosis cases in southern India, no attempts were made to identify the different MPSP-types in the mixed infections. MPSP-type 2 has been identified 
in Japan, China, Korea, Australia, and Brazil (Fig. 3) (Eamens et al., 2013; Kang et al., 2012; Ota et al., 2009; Sivakumar et al., 2011; Yokoyama et al., 2011). It is noteworthy that most of these countries have experienced clinical outbreaks caused by $T$. orientalis in their cattle populations (Eamens et al., 2013; Kamau et al., 2011; Kobayashi et al., 1991; Minami et al., 1980). In addition to genetic diversity in the parasite, the breed of cattle can also play a significant role in parasite virulence. In an experimental infection, Terada et al. (1995) found that Japanese Black calves were relatively resistant to $T$. orientalis infection, as characterized by lower parasitemias and higher minimum hematocrits and RBC counts than those of Holstein calves. In addition, despite the Japanese Black cattle being used to infection with several MPSP-types, including type 2 (Yokoyama et al. (2011), the animals seldom showed signs of anemia (Ota et al., 2009).

The genotypic distribution of $T$. orientalis has been investigated in different host animals. Differences in the MPSP-types were found not only between the host species but also among geographically different regions, as summarized in Fig. 4. Type-6 was detected in cattle and yaks, but not in water buffaloes, while the N1 type was detected only in water buffaloes (Liu et al., 2010; Sarataphan et al., 2003; Sivakumar et al., 2014). The N1 type of the MPSP gene sequence is 3 bp longer than other MPSP-types, except for type 6 (Kawazu et al., 1999; Sivakumar et al., 2014). Based on their host specificity and genetic variation, Kawazu et al. (1999) proposed that the N1 genotype should be classified as a different species of Theileria. Types 2 and 8 are predominant among cattle populations (Kang et al., 2012; Perera et al., 2013; Yokoyama et al., 2011), although we recently detected type 2 in a water buffalo bred in Egypt (manuscript submitted). However, the buffalo populations in the type 2-endemic countries have not been surveyed for T. orientalis MPSP-types as yet, and therefore further studies are essential to confirm the host specificity of types 2 and 8 . Nevertheless, we suggest that, in general, there is a relationship between host specificity and 
MPSP-types in T. orientalis. Although several T. orientalis genotypes occur commonly among cattle and water buffaloes, cross-infection profiles between these host animals were different in some of the endemic countries, possibly due to the differences in the transmission vectors. For example, although the cattle populations in Sri Lanka were infected with types 1, 3, 5, and 7, N1 and N2 were the only types detected in buffaloes (Figs. 3 and 4) (Sivakumar et al., 2013, 2014). While there is no specific barrier for the transmission of cattle-derived MPSP-types to buffaloes, as types 1, 3, 5, and 7 were also found in water buffaloes bred in other countries (Altangerel et al., 2011b; Khukhuu et al., 2011), the transmission of these genotypes was somehow limited in Sri Lanka (Sivakumar et al., 2014). The differences in the tick species feeding on the cattle and water buffaloes (Dovaudi et al., 2008) may explain the differences in the genotypes that infect these host animals in Sri Lanka. However, further studies are essential to identify the tick species that may transmit $T$. orientalis to the cattle and buffaloes in this country.

Genetic diversity in parasite populations has the potential to greatly impact the control of Theileria species. For example, improved knowledge of genetic diversity in T. parva may allow researchers to identify the source of infection and predict the epidemiology of an ongoing outbreak. For T. orientalis, investigation of MPSP-types could provide useful information about the severity of the infections caused by this species. Thus, investigation of genetic diversity in $T$. orientalis would enable veterinary authorities to identify appropriate control measures to combat infection with this species.

\section{Concluding remarks}

Attempts to unravel the evolutionary history of the piroplasmids, an order that includes Theileria parasites, has created controversy among researchers. However, what most 
researchers agree on is that our current knowledge does not provide a complete evolutionary picture of these parasites. The roles played by amphibians and reptiles have never been examined in the evolutionary studies, although, according to a report by Schnittger et al. (2012), they could have been involved in the early evolution of the piroplasmid ancestors. Therefore, more comprehensive studies linking various host species, such as mammals, birds, amphibians, and reptiles with their tick vectors and the piroplasmids may provide a clearer picture of piroplasmid evolution. Nephromyces species show marked differences from the piroplasmids, although they form a sister clade in the phylogram (Saffo et al., 2010). While all the piroplasmids are obligatory intracellular parasites by nature, Nephromyces species survive in the extracellular compartments of their hosts (Saffo et al., 2010). Therefore, including Nephromyces in future evolutionary studies may produce more meaningful conclusions.

Much research has been done to genetically characterize Theileria species. Whole genome sequences of the three major Theileria species of economic significance (T. parva, $T$. annulata, and $T$. orientalis) are now annotated and available for comprehensive examination (Gardner et al., 2005; Pain et al., 2005; Hayashida et al., 2012). In the past, many studies on genetic diversity in Theileria were restricted to investigating single genes; however, researchers can now use the data from whole genome sequencing for genome-wide diversity studies (Hayashida et al., 2013). Certainly, benefits can be gained from comparing the nontransforming and transforming Theileria genomes for identification of the host-cell transforming determinants (Hayashida et al., 2012). In future, comparisons of the genetic characters of $T$. parva and T. taurotragi may also provide insight as to why the latter has low pathogenicity in cattle, despite both parasites being phylogenetically close to each other (Allsopp et al., 1994; Gubbels et al., 2000a; Lack et al., 2012). Subsequently, detection of genetic variation between these two parasite species may allow researchers to list the genetic 
determinants related to the virulence characteristics of T. parva and T. annulata. Similarly, comparative genomic analysis of T. parva and Theileria sp. (buffalo) might shed an additional light on the host specificity and pathogenicity differences between these parasite species. Regarding molecular vaccines, several researchers have proposed that a cocktail containing the antigenic determinants targeting sporozoite neutralization, $\mathrm{CD}^{+} \mathrm{T}$ cells, and CTL may be effective against infection with Theileria parasites (McKeever et al., 1999; Preston et al., 1999). However, genetic diversity, among other factors, could have a negative influence on the development of such vaccination strategies. Nevertheless, studies on genetic diversity are relatively limited in $T$. orientalis, and almost all of them are based on MPSP. The recently completed genome project has paved the way for diversification of the research effort related to genetic variation in Theileria parasites (Hayashida et al., 2012). After characterization of vaccine candidates, the newly detected antigens should be investigated for their genetic diversity within the parasite population.

It is well known that recombination, which occurs in tick vectors during sexual reproduction, is the primary mechanism generating genetic diversity in Theileria parasites. While detailed studies on recombination are available for $T$. parva, recombination in $T$. annulata and $T$. orientalis remains a relatively untouched area of research. In particular, investigating genetic recombination between $T$. orientalis sub-populations belonging to different MPSP-types has the potential to resolve the debate on the taxonomic classification of this parasite species. Although past studies have provided insight into the evolution of and genetic diversity within Theileria parasites, more comprehensive investigations are required to gain better understanding of the evolutionary behavior of Theileria so that immunologically sound control strategies targeting these economically important parasites can be designed. 


\section{Acknowledgments}

This work was supported by grants from the Science and Technology Research Promotion Program for Agriculture, Forestry, Fisheries and Food Industry, from the Japan Society for Promotion of Science (JSPS) Grant-in-Aid for Scientific Research, and from the JST/JICA, Science and Technology Research Partnership for Sustainable Development (SATREPS). We are thankful to two anonymous reviewers for their constructive comments that greatly improved the manuscript. 


\section{References}

Ahmed, J.S., Luo, J., Schnittger, L., Seitzer, U., Jongejan, F., Yin, H., 2006. Phylogenetic position of small-ruminant infecting piroplasms. Ann. N. Y. Acad. Sci. 1081, 498-504.

Al-Khedery, B., Allred, D.R., 2006. Antigenic variation in Babesia bovis occurs through segmental gene conversion of the ves multigene family, within a bidirectional locus of active transcription. Mol. Microbiol. 59, 402-414.

Allsopp, B.A., Baylis, H.A., Allsopp, M.T., Cavalier-Smith, T., Bishop, R.P., Carrington, DM., Sohanpal, B., Spooner, P., 1993. Discrimination between six species of Theileria using oligonucleotide probes which detect small subunit ribosomal RNA sequences. Parasitology 107, 157-165.

Allsopp, M.T., Cavalier-Smith, T., De Waal, D.T., Allsopp, B.A., 1994. Phylogeny and evolution of the piroplasms. Parasitology 108, 147-152.

Altangerel, K., Battsetseg, B., Battur, B., Sivakumar, T., Batmagnai, E., Javkhlan, G., Tuvshintulga, B., Igarashi, I., Matsumoto, K., Inokuma, H., Yokoyama, N., 2011a. The first survey of Theileria orientalis infection in Mongolian cattle. Vet. Parasitol. 182, 343-348. 
Altangerel, K., Sivakumar, T., Inpankaew, T., Jittapalapong, S., Terkawi, M.A., Ueno, A., Xuan, X., Igarashi, I., Yokoyama, N., 2011b. Molecular prevalence of different genotypes of Theileria orientalis detected from cattle and water buffaloes in Thailand. J. Parasitol. 97, 1075-1079.

Aparna, M., Ravindran, R., Vimalkumar, M.B., Lakshmanan, B., Rameshkumar, P., Kumar, K.G., Promod, K., Ajithkumar, S., Ravishankar, C., Devada, K., Subramanian, H., George, A.J., Ghosh, S., 2011. Molecular characterization of Theileria orientalis causing fatal infection in crossbred adult bovines of South India. Parasitol. Int. 60, 524-529.

Ballingall, K.T., Luyai, A., Rowlands, G.J., Sales, J., Musoke, A.J., Morzaria, S.P., McKeever, D.J., 2004. Bovine leukocyte antigen major histocompatibility complex class II DRB3*2703 and DRB3*1501 alleles are associated with variation in levels of protection against Theileria parva challenge following immunization with the sporozoite p67 antigen. Infect. Immun. 72, 2738-2741.

Baylis, H.A., Sohal, S.K., Carrington, M., Bishop, R.P., Allsopp, B.A., 1991. An unusual repetitive gene family in Theileria parva which is stage-specifically transcribed. Mol. Biochem. Parasitol. 49, 133-42.

Bishop, R., Musoke, A., Morzaria, S., Gardner, M., Nene, V., 2004. Theileria: intracellular protozoan parasites of wild and domestic ruminants transmitted by ixo did ticks. Parasitology 129 (Suppl.), S271-283. 
Bishop, R., Musoke, A., Morzaria, S., Sohanpal, B., Gobright, E., 1997. Concerted evolution at a multicopy locus in the protozoan parasite Theileria parva: extreme divergence of potential protein-coding sequences. Mol. Cell Biol. 17, 1666-1673.

Boulter, N.R., Brown, C.G., Kirvar, E., Glass, E., Campbell, J., Morzaria, S., Nene, V., Musoke, A., D'Oliveira, C., Gubbels, M.J., Jongejan, F., Hall, F.R., 1998. Different vaccine strategies used to protect against Theileria annulata. Ann. N. Y. Acad. Sci. 849, 234-46.

Boulter, N., Brown, D., Wilkie, G., Williamson, S., Kirvar, E., Knight, P., Glass, E., Campbell, J., Morzaria, S., Nene, V., Musoke, A., d'Oliveira, C., Gubbels, M.J., Jongejan, F., Hall, R., 1999. Evaluation of recombinant sporozoite antigen SPAG-1 as a vaccine candidate against Theileria annulata by the use of different delivery systems. Trop. Med. Int. Health 4, A71-77.

Boulter, N.R., Glass, E.J., Knight, P.A., Bell-Sakyi, L., Brown, C.G., Hall, R., 1995. Theileria annulata sporozoite antigen fused to hepatitis B core antigen used in a vaccination trial. Vaccine 13, 1152-1160.

Boulter, N., Knight, P.A., Hunt, P.D., Hennessey, E.S., Katzer, F., Tait, A., Williamson, S., Brown, D., Baylis, H.A., Hall, R., 1994. Theileria annulata sporozoite surface antigen (SPAG-1) contains neutralizing determinants in the C terminus. Parasite Immunol. 16, 97104. 
Brayton, K.A., Lau, A.O., Herndon, D.R., Hannick, L., Kappmeyer, L.S., Berens, S.J., Bidwell, S.L., Brown, W.C., Crabtree, J., Fadrosh, D., Feldblum, T., Forberger, H.A., Haas, B.J., Howell, J.M., Khouri, H., Koo, H., Mann, D.J., Norimine, J., Paulsen, I.T., Radune, D., Ren, Q., Smith, R.K. Jr., Suarez, C.E., White, O., Wortman, J.R., Knowles, D.P. Jr., McElwain, T.F., Nene, V.M., 2007. Genome sequence of Babesia bovis and comparative analysis of apicomplexan hemoprotozoa. PLoS Pathog. 3, 1401-1413.

Camacho, A.T., Pallas, E., Gestal, J.J., Guitián, F.J., Olmeda, A.S., Goethert, H.K., Telford, S.R., 2001. Infection of dogs in north-west Spain with a Babesia microti-like agent. Vet Rec. 149, 552-555.

Chaisi, M.E., Sibeko, K.P., Collins, N.E., Potgieter, F.T., Oosthuizen, M.C., 2011. Identification of Theileria parva and Theileria sp. (buffalo) 18S rRNA gene sequence variants in the African Buffalo (Syncerus caffer) in southern Africa. Vet. Parasitol. 182, 150162.

Charlesworth, B., 2009. Fundamental concepts in genetics: effective population size and patterns of molecular evolution and variation. Nat. Rev. Genet. 10, 195-205.

Ciancio, A., Scippa, S., Finetti-Sialer, M., De Candia, A., Avallone, B., De Vincentiis, M., 2008. Redescription of Cardiosporidium cionae (Van Gaver and Stephan, 1907) (Apicomplexa: Piroplasmida), a plasmodial parasite of ascidian haemocytes. Eur. J. Protistol. 44, 181-196. 
Connelley, T.K., MacHugh, N.D., Pelle, R., Weir, W., Morrison, W.I., 2011. Escape from CD8+ $\mathrm{T}$ cell response by natural variants of an immunodominant epitope from Theileria parva is predominantly due to loss of TCR recognition. J. Immunol. 187, 5910-5920.

Conrad, P.A., Denham, D., Brown, C.G., 1986. Intraerythrocytic multiplication of Theileria parva in vitro: an ultrastructural study. Int. J. Parasitol. 16, 223-229.

Conrad, P.A., Stagg, D.A., Grootenhuis, J.G., Irvin, A.D., Newson, J., Njamunggeh, R.E., Rossiter, P.B., Young, A.S., 1987. Isolation of Theileria parasites from African buffalo (Syncerus caffer) and characterization with anti-schizont monoclonal antibodies. Parasitology 94, 413-423.

Conway, D.J., Roper, C., Oduola, A.M., Arnot, D.E., Kremsner, P.G., Grobusch, M.P., Curtis, C.F., Greenwood, B.M., 1999. High recombination rate in natural populations of Plasmodium falciparum. Proc. Natl. Acad. Sci. USA. 96, 4506-4511.

Cornillot, E., Hadj-Kaddour, K., Dassouli, A., Noel, B., Ranwez, V., Vacherie, B., Augagneur, Y., Brès, V., Duclos, A., Randazzo, S., Carcy, B., Debierre-Grockiego, F., Delbecq, S., Moubri-Ménage, K., Shams-Eldin, H., Usmani-Brown, S., Bringaud, F., Wincker, P., Vivarès, C.P., Schwarz, R.T., Schetters, T.P., Krause, P.J., Gorenflot, A., Berry, V., Barbe, V., Ben Mamoun, C., 2012. Sequencing of the smallest apicomplexan genome from the human pathogen Babesia microti. Nucleic Acids Res. 40, 9102-9114. 
Criado-Fornelio, A., Martinez-Marcos, A., Buling-Saraña, A., Barba-Carretero, J.C., 2003. Molecular studies on Babesia, Theileria and Hepatozoon in southern Europe Part II. Phylogenetic analysis and evolutionary history. Vet. Parasitol. 114, 173-194.

Deitsch, K.W., Lukehart, S.A., Stringer, J.R., 2009. Common strategies for antigenic variation by bacterial, fungal and protozoan pathogens. Nat. Rev. Microbiol. 7, 493-503.

Dobbelaere, D., Heussler, V., 1999. Transformation of leukocytes by Theileria parva and T. annulata. Annu. Rev. Microbiol. 53, 1-42.

Dobbelaere, D.A., Küenzi, P., 2004. The strategies of the Theileria parasite: a new twist in host-pathogen interactions. Curr. Opin. Immunol. 16, 524-530.

Dovaudi, J., Rad, N.H., Adabi, S.G., 2008. Ixodid tick species infesting cows and buffaloes and their seasonality in West Azerbaijan. Res. J. Parasitol. 3, 98-103.

Duret, L., Galtier, N., 2009. Biased gene conversion and the evolution of mammalian genomic landscapes. Annu. Rev. Genomics Hum. Genet. 10, 285-311.

Eamens, G.J., Gonsalves, J.R., Jenkins, C., Collins, D., Bailey, G., 2013. Theileria orientalis MPSP types in Australian cattle herds associated with outbreaks of clinical disease and their association with clinical pathology findings. Vet. Parasitol. 191, 209-217. 
Feng, X., Rich, S.M., Tzipori, S., Widmer, G., 2002. Experimental evidence for genetic recombination in the opportunistic pathogen Cryptosporidium parvum. Mol. Biochem. Parasitol. 119, 55-62.

Florin-Christensen, M., Schnittger, L., 2009. Piroplasmids and ticks: a long-lasting intimate relationship. Front. Biosci. (Landmark Ed). 14, 3064-3073.

Frankham, R., Briscoe, D.A., Nurthen, R.K., 1980. Unequal crossing over at the rRNA tandon as a source of quantitative genetic variation in Drosophila. Genetics 95, 727-742.

Freeman, A.R., Hoggart, C.J., Hanotte, O., Bradley, D.G., 2006. Assessing the relative ages of admixture in the bovine hybrid zones of Africa and the Near East using $\mathrm{X}$ chromosome haplotype mosaicism. Genetics. 173, 1503-1510.

Fujisaki, K., 1992. A review of the taxonomy of Theileria sergenti/buffeli/orientalis group parasites in cattle. J. Protozool. Res. 2, 87-96.

Fujisaki, K., Kawazu, S., Kamio, T., 1994. The taxonomy of the bovine Theileria spp. Parasitol. Today 10, 31-33.

Fukumoto, S., Suzuki, H., Igarashi, I., Xuan, X., 2005. Fatal experimental transplacental Babesia gibsoni infections in dogs. Int. J. Parasitol. 35, 1031-1035 
Galtier, N., Piganeau, G., Mouchiroud, D., Duret, L., 2001. GC-content evolution in mammalian genomes: the biased gene conversion hypothesis. Genetics 159, 907-911.

Gardner, M.J., Bishop, R., Shah, T., de Villiers, E.P., Carlton, J.M., Hall, N., Ren, Q., Paulsen, I.T., Pain, A., Berriman, M., Wilson, R.J., Sato, S., Ralph, S.A., Mann, D.J., Xiong, Z., Shallom, S.J., Weidman, J., Jiang, L., Lynn, J., Weaver, B., Shoaibi, A., Domingo, A.R., Wasawo, D., Crabtree, J., Wortman, J.R., Haas, B., Angiuoli, S.V., Creasy, T.H., Lu, C., Suh, B., Silva, J.C., Utterback, T.R., Feldblyum, T.V., Pertea, M., Allen, J., Nierman, W.C., Taracha, E.L., Salzberg, S.L., White, O.R., Fitzhugh, H.A., Morzaria, S., Venter, J.C., Fraser, C.M., Nene, V., 2005. Genome sequence of Theileria parva, a bovine pathogen that transforms lymphocytes. Science. 309, 134-137.

Geysen, D., Bazarusanga, T., Brandt, J., Dolan, T.T., 2004. An unusual mosaic structure of the PIM gene of Theileria parva and its relationship to allelic diversity. Mol. Biochem. Parasitol. 133, 163-173.

Goddeeris, B.M., Morrison, W.I., Toye, P.G., Bishop, R., 1990. Strain specificity of bovine Theileria parva-specific cytotoxic T cells is determined by the phenotype of the restricting class I MHC. Immunology. 69, 38-44.

Gou, H., Guan, G., Liu, A., Ma, M., Chen, Z., Liu, Z., Ren, Q., Li, Y., Yang, J., Yin, H., Luo, J., 2013. Coevolutionary analyses of the relationships between piroplasmids and their hard tick hosts. Ecol. Evol. 3, 2985-2993. 
Graham, S.P., Pellé, R., Honda, Y., Mwangi, D.M., Tonukari, N.J., Yamage, M., Glew, E.J., de Villiers, E.P., Shah, T., Bishop, R., Abuya, E., Awino, E., Gachanja, J., Luyai, A.E., Mbwika, F., Muthiani, A.M., Ndegwa, D.M., Njahira, M., Nyanjui, J.K., Onono, F.O., Osaso, J., Saya, R.M., Wildmann, C., Fraser, C.M., Maudlin, I., Gardner, M.J., Morzaria, S.P., Loosmore, S., Gilbert, S.C., Audonnet, J.C., van der Bruggen, P., Nene, V., Taracha, E.L., 2006. Theileria parva candidate vaccine antigens recognized by immune bovine cytotoxic $\mathrm{T}$ lymphocytes. Proc. Natl. Acad. Sci. 103, 3286-3291.

Graham, S.P., Pellé, R., Yamage, M., Mwangi, D.M., Honda, Y., Mwakubambanya, R.S., de Villiers, E.P., Abuya, E., Awino, E., Gachanja, J., Mbwika, F., Muthiani, A.M., Muriuki, C., Nyanjui, J.K., Onono, F.O., Osaso, J., Riitho, V., Saya, R.M., Ellis, S.A., McKeever, D.J., MacHugh, N.D., Gilbert, S.C., Audonnet, J.C., Morrison, W.I., van der Bruggen, P., Taracha, E.L., 2008. Characterization of the fine specificity of bovine CD8 T-cell responses to defined antigens from the protozoan parasite Theileria parva. Infect. Immun. 76, 685-694.

Gubbels, M.J., Hong, Y., van der Weide, M., Qi, B., Nijman, I.J., Guangyuan, L., Jongejan, F., 2000a. Molecular characterisation of the Theileria buffeli/orientalis group. Int. J. Parasitol. 30, 943-952.

Gubbels, M.J., Katzer, F., Hide, G., Jongejan, F., Shiels, B.R., 2000b. Generation of a mosaic pattern of diversity in the major merozoite-piroplasm surface antigen of Theileria annulata. Mol. Biochem. Parasitol. 110, 23-32. 
Gubbels, M.J., Katzer, F., Shiels, B.R., Jongejan, F., 2001. Study of Theileria annulata population structure during bovine infection and following transmission to ticks. Parasitology 123, 553-561.

Hall, R., Boulter, N.R., Brown, C.G., Wilkie, G., Kirvar, E., Nene, V., Musoke, A.J., Glass, E.J., Morzaria, S.P., 2000. Reciprocal cross-protection induced by sporozoite antigens SPAG-1 from Theileria annulata and p67 from Theileria parva. Parasite Immunol. 22, 223230.

Hasegawa, M., Kishino, H., Yano, T., 1985. Dating of the human-ape splitting by a molecular clock of mitochondrial DNA. J. Mol. Evol. 22, 160-174.

Hayashida, K., Abe, T., Weir, W., Nakao, R., Ito, K., Kajino, K., Suzuki, Y., Jongejan, F., Geysen, D., Sugimoto, C., 2013. Whole-genome sequencing of Theileria parva strains provides insight into parasite migration and diversification in the African continent. DNA Res. 20, 209-220.

Hayashida, K., Hara, Y., Abe, T., Yamasaki, C., Toyoda, A., Kosuge, T., Suzuki, Y., Sato, Y., Kawashima, S., Katayama, T., Wakaguri, H., Inoue, N., Homma, K., Tada-Umezaki, M., Yagi, Y., Fujii, Y., Habara, T., Kanehisa, M., Watanabe, H., Ito, K., Gojobori, T., Sugawara, H., Imanishi, T., Weir, W., Gardner, M., Pain, A., Shiels, B., Hattori, M., Nene, V., Sugimoto, C., 2012. Comparative genome analysis of three eukaryotic parasites with differing abilities to transform leukocytes reveals key mediators of Theileria-induced leukocyte transformation. MBio. 3(5):e00204-12. 
Henson, S., Bishop, R.P., Morzaria, S., Spooner, P.R., Pelle, R., Poveda, L., Ebeling, M., Küng, E., Certa, U., Daubenberger, C.A., Qi, W., 2012. High-resolution genotyping and mapping of recombination and gene conversion in the protozoan Theileria parva using whole genome sequencing. BMC Genomics 13, 503.

Hoeijmakers, J.H., Frasch, A.C., Bernards, A., Borst, P., Cross, G.A., 1980. Novel expression-linked copies of the genes for variant surface antigens in trypanosomes. Nature. 284, 78-80.

Höfle, U., Vicente, J., Nagore, D., Hurtado, A., Peña, A., de la Fuente, J., Gortazar, C., 2004. The risks of translocating wildlife. Pathogenic infection with Theileria sp. and Elaeophora elaphi in an imported red deer. Vet. Parasitol. 126, 387-395.

Homer, M.J., Aguilar-Delfin, I., Telford, S.R., Krause, P.J., Persing, D.H., 2000. Babesiosis. Clin. Microbiol. Rev. 13, 451-469.

Honda, Y., Waithaka, M., Taracha, E.L., Duchateau, L., Musoke, A.J., McKeever, D.J., 1998. Delivery of the Theileria parva p67 antigen to cattle using recombinant vaccinia virus: IL-2 enhances protection. Vaccine 16, 1276-1282.

Irvin, A.D., Mwamachi, D.M., 1983. Clinical and diagnostic features of East Coast fever (Theileria parva) infection of cattle. Vet. Rec. 113, 192-198. 
Iwasaki, T., Kakuda, T., Sako, Y., Sugimoto, C., Onuma, M., 1998. Differentiation and quantification of Theileria sergenti piroplasm types using type-specific monoclonal antibodies. J. Vet. Med. Sci. 60, 665-669.

Jefferies, R., Ryan, U.M., Jardin, J., Broughton, D.K, Robertson, I.D., Irwin, P.J., 2007. Blood, Bull terriers and babesiosis: further evidence for direct transmission of Babesia gibsoni in dogs. Aust. Vet. J. 85, 459-463.

Jensen-Seaman, M.I., Furey, T.S., Payseur, B.A., Lu, Y., Roskin, K.M., Chen, C.F., Thomas, M.A., Haussler, D., Jacob, H.J., 2004. Comparative recombination rates in the rat, mouse, and human genomes. Genome Res. 14, 528-538.

Jeong, W., Yoon, S.H., An, D.J., Cho, S.H., Lee, K.K., Kim, J.Y., 2010. A molecular phylogeny of the benign Theileria parasites based on major piroplasm surface protein (MPSP) gene sequences. Parasitology 137, 241-249.

Jiang, H., Li, N., Gopalan, V., Zilversmit, M.M., Varma, S., Nagarajan, V., Li, J., Mu, J., Hayton, K., Henschen, B., Yi, M., Stephens, R., McVean, G., Awadalla, P., Wellems, T.E., Su, X.Z., 2011. High recombination rates and hotspots in a Plasmodium falciparum genetic cross. Genome Biol. 12, R33.

Joseph, J.T., Purtill, K., Wong, S.J., Munoz, J., Teal, A., Madison-Antenucci, S., Horowitz, H.W., Aguero-Rosenfeld, M.E., Moore, J.M., Abramowsky, C., Wormser, G.P., 2012. Vertical transmission of Babesia microti, United states. Emerg. Infect. Dis. 18, 1318-1321. 
Kakuda, T., Kubota, S., Sugimoto, C., Baek, B.K., Yin, H., Onuma, M., 1998. Analysis of immunodominant piroplasm surface protein genes of benign Theileria parasites distributed in China and Korea by allele-specific polymerase chain reaction. J. Vet. Med. Sci. 60, 237-239.

Kakuda, T., Sugimoto, C., Onuma, M., 2001. Epitope-Mapping of antigen-specific T lymphocyte in cattle immunized with recombinant major piroplasm surface protein of Theileria sergenti. J. Vet. Med. Sci. 63, 895-901.

Kamau, J., de Vos, A.J., Playford, M., Salim, B., Kinyanjui, P., Sugimoto, C., 2011. Emergence of new types of Theileria orientalis in Australian cattle and possible cause of theileriosis outbreaks. Parasit. Vectors. 21, 4:22.

Kang, S.W., Nguyen, L.T., Noh, J.H., Reddy, K.E., Kweon, C.H., Choe, S.E., 2012. Phylogenetic analysis of benign Theileria species based on major piroplasm surface protein (MPSP) genes from ticks of grazing cattle in Korea. Vet. Parasitol. 189, 145-152.

Kappmeyer, L.S., Thiagarajan, M., Herndon, D.R., Ramsay, J.D., Caler, E., Djikeng, A., Gillespie, J.J., Lau, A.O., Roalson, E.H., Silva, J.C., Silva, M.G., Suarez, C.E., Ueti, M.W., Nene, V.M., Mealey, R.H., Knowles, D.P., Brayton, K.A., 2012. Comparative genomic analysis and phylogenetic position of Theileria equi. BMC Genomics 13, 603. 
Katende, J., Morzaria, S., Toye, P., Skilton, R., Nene, V., Nkonge, C., Musoke, A., 1998. An enzyme-linked immunosorbent assay for detection of Theileria parva antibodies in cattle using a recombinant polymorphic immunodominant molecule. Parasitol. Res. 84, 408-416.

Katoh, K., Misawa, K., Kuma, K., Miyata, T., 2002. MAFFT: a novel method for rapid multiple sequence alignment based on fast Fourier transform. Nucleic Acids Res. 30, 30593066.

Katzer, F., Carrington, M., Knight, P., Williamson, S., Tait, A., Morrison, I.W., Hall, R., 1994. Polymorphism of SPAG-1, a candidate antigen for inclusion in a sub-unit vaccine against Theileria annulata. Mol. Biochem. Parasitol. 67, 1-10.

Katzer, F., Lizundia, R., Ngugi, D., Blake, D., McKeever, D., 2011. Construction of a genetic map for Theileria parva: identification of hotspots of recombination. Int. J. Parasitol. 41, $669-675$.

Katzer, F., McKellar, S., Ben Miled, L., D'Oliveira, C., Shiels, B., 1998. Selection for antigenic diversity of Tams1, the major merozoite antigen of Theileria annulata. Ann. N. Y. Acad. Sci. 849, 96-108.

Katzer, F., Ngugi, D., Oura, C., Bishop, R.P., Taracha, E.L., Walker, A.R., McKeever, D.J., 2006. Extensive genotypic diversity in a recombining population of the apicomplexan parasite Theileria parva. Infect. Immun. 74, 5456-5464. 
Kawamoto, S., Takahashi, K., Kurosawa, T., Sonoda, M., Onuma, M., 1990. Intraerythrocytic schizogony of Theileria sergenti in cattle. Nihon Juigaku Zasshi 52, 12511259.

Kawazu, S., Kamio, T., Kakuda, T., Terada, Y., Sugimoto, C., Fujisaki, K., 1999. Phylogenetic relationships of the benign Theileria species in cattle and Asian buffalo based on the major piroplasm surface protein (p33/34) gene sequences. Int. J. Parasitol. 29, 613618.

Khan, A., Taylor, S., Su, C., Mackey, A.J., Boyle, J., Cole, R., Glover, D., Tang, K., Paulsen, I.T., Berriman, M., Boothroyd, J.C., Pfefferkorn, E.R., Dubey, J.P., Ajioka, J.W., Roos, D.S., Wootton, J.C., Sibley, L.D., 2005. Composite genome map and recombination parameters derived from three archetypal lineages of Toxoplasma gondii. Nucleic Acids Res. 33, 29802992.

Khukhuu, A., Lan, D.T., Long, P.T., Ueno, A., Li, Y., Luo, Y., Macedo, A.C., Matsumoto, K., Inokuma, H., Kawazu, S.I., Igarashi, I., Xuan, X., Yokoyama, N., 2011. Molecular epidemiological survey of Theileria orientalis in Thua Thien Hue. J. Vet. Med. Sci. 73, 701705.

Kim, S.J., Tsuji, M., Kubota, S., Wei, Q., Lee, J.M., Ishihara C., Onuma, M., 1998. Sequence analysis of the major piroplasm surface protein gene of benign bovine Theileria parasites in east Asia. Int. J. Parasitol. 28, 1219-1227. 
Kjemtrup, A.M., Robinson, T., Conrad, P.A., 2001. Description and epidemiology of Theileria youngi n. sp. from a northern Californian dusky-footed woodrat (Neotoma Fuscipes) population.J. Parasitol. 87, 373-378.

Knight, P., Musoke, A.J., Gachanja, J.N., Nene, V., Katzer, F., Boulter, N., Hall, R., Brown, C.G., Williamson, S., Kirvar, E., Bell-Sakyi, L., Hussain, K., Tait, A., 1996. Conservation of neutralizing determinants between the sporozoite surface antigens of Theileria annulata and Theileria parva. Exp. Parasitol. 82, 229-241.

Kobayashi, S., Yataya, K., Takayama, S., 1991. Growth of dairy heifers and outbreak of Japanese theileriosis in pastures contaminated with its carrier (in Japanese). Jpn. J. Livestock Management 26, 82-88.

Lack, J.B., Reichard, M.V., Van Den Bussche, R.A., 2012. Phylogeny and evolution of the Piroplasmida as inferred from 18S rRNA sequences. Int. J. Parasitol. 42, 353-463.

Liu, A., Guan, G., Liu, Z., Liu, J., Leblanc, N., Li, Y., Gao, J., Ma, M., Niu, Q., Ren, Q., Bai, Q., Yin, H., Luo, J., 2010. Detecting and differentiating Theileria sergenti and Theileria sinensis in cattle and yaks by PCR based on major piroplasm surface protein (MPSP). Exp. Parasitol. 126, 476-81.

Livingstone, F.B., 1972. Genetic drift and polygenic inheritance. Am. J. Phys. Anthrop. 37, 
$117-126$.

MacHugh, N.D., Burrells, A.C., Morrison, W.I., 2008. Demonstration of strain-specific CD8 T cell responses to Theileria annulata. Parasite Immunol. 30, 385-393.

MacHugh, N.D., Connelley, T., Graham, S.P., Pelle, R., Formisano, P., Taracha, E.L., Ellis, S.A., McKeever, D.J., Burrells, A., Morrison, W.I., 2009. CD8+ T-cell responses to Theileria parva are preferentially directed to a single dominant antigen: Implications for parasite strain-specific immunity. Eur. J. Immunol. 39, 2459-2469.

MacHugh, N.D., Weir, W., Burrells, A., Lizundia, R., Graham, S.P., Taracha, E.L., Shiels, B.R., Langsley, G., Morrison, W.I., 2011. Extensive polymorphism and evidence of immune selection in a highly dominant antigen recognized by bovine CD8 $\mathrm{T}$ cells specific for Theileria annulata. Infect. Immun. 79, 2059-2069.

Mans, B.J., Pienaar, R., Latif, A.A., Potgieter, F.T., 2011a. Diversity in the 18S SSU rRNA V4 hyper-variable region of Theileria spp. in Cape buffalo (Syncerus caffer) and cattle from southern Africa. Parasitology 138, 766-779.

Mans, B.J., Pienaar, R., Potgieter, F.T., Latif, A.A., 2011b. Theileria parva, T. sp. (buffalo) and T. sp. (bougasvlei) 18S variants. Vet. Parasitol. 182, 382-383.

Martinelli, A., Hunt, P., Fawcett, R., Cravo, P.V., Walliker, D., Carter, R., 2005. An AFLPbased genetic linkage map of Plasmodium chabaudi chabaudi. Malar. J. 4, 11. 
McFadden, A.M., Rawdon, T.G., Meyer, J., Makin, J., Clough, R.R., Tham, K., Mullner, P., Geysen, D., 2011. An outbreak of haemolytic anaemia associated with infection of Theileria orientalis in naive cattle. N. Z. Vet. J. 59, 79-85.

McKeever, D.J., 2009. Bovine immunity - a driver for diversity in Theileria parasites? Trends Parasitol. 25, 269-276.

McKeever, D.J., Taracha, E.L., Innes, E.L., MacHugh, N.D., Awino, E., Goddeeris, B.M., Morrison, W.I., 1994. Adoptive transfer of immunity to Theileria parva in the CD8+ fraction of responding efferent lymph. Proc. Natl. Acad. Sci. 91, 1959-1963.

McKeever, D.J., Taracha, E.L., Morrison, W.I., Musoke, A.J., Morzaria, S.P., 1999. Protective immune mechanisms against Theileria parva: Evolution of vaccine development strategies. Parasitol. Today 15, 263-267.

Mehlhorn, H., Raether, W., Schein, E., Weber, M., Uphoff, M., 1986. Light and electron microscopic studies on the life cycle of Babesia microti and the effects of pentamidine on the intraerythrocytic stages (in German). Deutsche Tierarztliche Wochenschrift 93, 400-405.

Mehlhorn, H., Schein, E., 1998. Redescription of Babesia equi Laveran, 1901 as Theileria equi Mehlhorn, Schein 1998. Parasitol. Res. 84, 467-475. 
Minami, T., Fujinaga, T., Furuya, K., Ishihara, T., 1980. Clinico-hematologic and serological comparison of Japanese and Russian strains of Theileria sergenti. Natl. Inst. Anim. Health. Q. (Jpn). 20, 44-52.

Minot, S., Melo, M.B., Li, F., Lu, D., Niedelman, W., Levine, S.S., Saeij, J.P., 2012. Admixture and recombination among Toxoplasma gondii lineages explain global genome diversity. Proc. Natl. Acad. Sci. USA. 109, 13458-13463.

Morzaria, S., Nene, V., Bishop, R., Musoke, A., 2000. Vaccines against Theileria parva. Ann. N. Y. Acad. Sci. 916, 464-473

Morzaria, S.P., Young, J.R., Spooner, P.R., Dolan, T.T., Bishop, R.P., 1993. Theileria parva: A restriction map and genetic recombination, in: Mozaria, S.P. (Ed.), Genome Analysis of Protozoan Parasites. ILRAD, Nairobi, pp. 67-73.

Musoke, A.J., Morzaria, S., Nkonge, C., Jones, E., Nene, V., 1992. A recombinant sporozoite surface antigen of Theileria parva induces protection in cattle. Proc. Natl. Acad. Sci. 89, $524-518$.

Myler, P., Nelson, R.G., Agabian, N., Stuart, K., 1984. Two mechanisms of expression of a predominant variant antigen gene of Trypanosoma brucei. Nature. 309, 282-284.

Nambota, A., Samui, K., Sugimoto, C., Kakuta, T., Onuma, M., 1994. Theileriosis in Zambia: etiology, epidemiology and control measures. Jpn. J. Vet. Res. 42, 1-18. 
Nene, V., Gobright, E., Bishop, R., Morzaria, S., Musoke, A., 1999. Linear peptide specificity of bovine antibody responses to p67 of Theileria parva and sequence diversity of sporozoite-neutralizing epitopes: implications for a vaccine. Infect. Immun. 67, 1261-1266.

Nene, V., Musoke, A., Gobright, E., Morzaria, S., 1996. Conservation of the sporozoite p67 vaccine antigen in cattle-derived Theileria parva stocks with different cross-immunity profiles. Infect. Immun. 64, 2056-2061.

Nijhof, A.M., Pillay, V., Steyl, J., Prozesky, L., Stoltsz, W.H., Lawrence, J.A., Penzhorn, B.L., Jongejan, F., 2005. Molecular characterization of Theileria species associated with mortality in four species of African antelopes. J. Clin. Microbiol. 43, 5907-5911.

Onuma, M., Kakuda, T., Sugimoto, C., 1998. Theileria parasite infection in East Asia and control of the disease. Comp. Immunol. Microbiol. Infect. Dis. 21, 165-177.

Oosthuizen, M.C., Allsopp, B.A., Troskie, M., Collins, N.E., Penzhorn, B.L., 2009. Identification of novel Babesia and Theileria species in South African giraffe (Giraffa camelopardalis, Linnaeus, 1758) and roan antelope (Hippotragus equinus, Desmarest 1804). Vet. Parasitol. 163, 39-46.

Ota, N., Mizuno, D., Kuboki, N., Igarashi, I., Nakamura, Y., Yamashina, H., Hanzaike, T., Fujii, K., Onoe, S., Hata, H., Kondo, S., Matsui, S., Koga, M., Matsumoto, K., Inokuma H., 
Yokoyama N., 2009. Epidemiological survey of Theileria orientalis infection in grazing cattle in the Eastern Part of Hokkaido, Japan. J. Vet. Med. Sci. 71, 937-944.

Pain, A., Renauld, H., Berriman, M., Murphy, L., Yeats, C.A., Weir, W., Kerhornou, A., Aslett, M., Bishop, R., Bouchier, C., Cochet, M., Coulson, R.M., Cronin, A., de Villiers, E.P., Fraser, A., Fosker, N., Gardner, M., Goble, A., Griffiths-Jones, S., Harris, D.E., Katzer, F., Larke, N., Lord, A., Maser, P., McKellar, S., Mooney, P., Morton, F., Nene, V., O'Neil, S., Price, C., Quail, M.A., Rabbinowitsch, E., Rawlings, N.D., Rutter, S., Saunders, D., Seeger, K., Shah, T., Squares, R., Squares, S., Tivey, A., Walker, A.R., Woodward, J., Dobbelaere, D.A., Langsley, G., Rajandream, M.A., McKeever, D., Shiels, B., Tait, A., Barrell, B., Hall, N., 2005. Genome of the host-cell transforming parasite Theileria annulata compared with T. parva. Science. 309, 131-133.

Pelle, R., Graham, S.P., Njahira, M.N., Osaso, J., Saya, R.M., Odongo, D.O., Toye, P.G., Spooner, P.R., Musoke. A.J., Mwangi, D.M., Taracha, E.L., Morrison, W.I., Weir, W., Silva, J.C., Bishop, R.P., 2011. Two Theileria parva CD8 T cell antigen genes are more variable in buffalo than cattle parasites, but differ in pattern of sequence diversity. PLOS One. 6, e19015.

Perera, P.K., Gasser, R.B., Anderson, G.A., Jeffers, M., Bell, C.M., Jabbar, A., 2013. Epidemiological survey following oriental theileriosis outbreaks in Victoria, Australia, on selected cattle farms. Vet. Parasitol. 197, 509-521.

Pienaar, R., Latif, A.A., Thekisoe, O.M., Mans, B.J., 2014. Geographic distribution of Theileria sp. (buffalo) and Theileria sp. (bougasvlei) in Cape buffalo (Syncerus caffer) in 
southern Africa: implications for speciation. Parasitology 141, 411-424.

Pienaar, R., Potgieter, F.T., Latif, A.A., Thekisoe, O.M., Mans, B.J., 2011. The Hybrid II assay: a sensitive and specific real-time hybridization assay for the diagnosis of Theileria parva infection in Cape buffalo (Syncerus caffer) and cattle. Parasitology 138, 1935-1944.

Preston, P.M., Hall, F.R., Glass, E.J., Campbell, J.D., Darghouth, M.A., Ahmed, J.S., Shiels, B.R., Spooner, R.L., Jongejan, F., Brown, C.G., 1999. Innate and adaptive immune responses co-operate to protect cattle against Theileria annulata. Parasitol. Today 15, 268-274.

Saffo, M.B., McCoy, A.M., Rieken, C., Slamovits, C.H., 2010. Nephromyces, a beneficial apicomplexan symbiont in marine animals. Proc. Natl. Acad. Sci. 107, 16190-16195.

Sarataphan, N., Kakuda, T., Chansiri, K., Onuma, M., 2003. Survey of benign Theileria parasites of cattle and buffaloes in Thailand using allele-specific polymerase chain reaction of major piroplasm surface protein gene. J. Vet. Med. Sci. 65, 133-135.

Sarataphan, N., Nilwarangkoon, S., Tananyutthawongese, C., Kakuda, T., Onuma, M., Chansiri, K., 1999. Genetic diversity of major piroplasm surface protein genes and their allelic variants of Theileria parasites in Thai cattle. J. Vet. Med. Sci. 61, 991-994.

Sato, M., Kamio, T., Kawazu, S., Taniguchi, T., Minami, T., Fujisaki, K., 1993. Histological observations on the schizonts in cattle infected with Japanese Theileria sergenti. J. Vet. Med. Sci. 55, 571-574. 
Schmuckli-Maurer, J., Casanova, C., Schmied, S., Affentranger, S., Parvanova, I., Kang'a, S., Nene, V., Katzer, F., McKeever, D., Müller, J., Bishop, R., Pain, A., Dobbelaere, D.A., 2009. Expression analysis of the Theileria parva subtelomere-encoded variable secreted protein gene family. PLOS One. 4, e4839.

Schnittger, L., Katzer, F., Biermann, R., Shayan, P., Boguslawski, K., McKellar, S., Beyer, D., Shiels, B.R., Ahmed, J.S., 2002. Characterization of a polymorphic Theileria annulata surface protein (TaSP) closely related to PIM of Theileria parva: implications for use in diagnostic tests and subunit vaccines. Mol. Biochem. Parasitol. 120, 247-256.

Schnittger, L., Rodriguez, A.E., Florin-Christensen, M., Morrison, D.A., 2012. Babesia: a world emerging. Infect. Genet. Evol. 12, 1788-1809.

Seehausen, O., Butlin, R.K., Keller, I., Wagner, C.E., Boughman, J.W., Hohenlohe, P.A., Peichel, C.L., Saetre, G.P., Bank, C., Brännström, A., Brelsford, A., Clarkson, C.S., Eroukhmanoff, F., Feder, J.L., Fischer, M.C., Foote, A.D., Franchini, P., Jiggins, C.D., Jones, F.C., Lindholm, A.K., Lucek, K., Maan, M.E., Marques, D.A., Martin, S.H., Matthews, B., Meier, J.I., Möst, M., Nachman, M.W., Nonaka, E., Rennison, D.J., Schwarzer, J., Watson, E.T., Westram, A.M., Widmer, A., 2014. Genomics and the origin of species. Nat. Rev. Genet. 15, 176-92. 
Shaw, M.K., Tilney, L.G., 1992. How individual cells develop from a syncytium: merogony in Theileria parva (Apicomplexa). J. Cell. Sci. 101, 109-123.

Sibeko, K.P., Geysen, D., Oosthuizen, M.C., Matthee, C.A., Troskie, M., Potgieter, F.T., Coetzer, J.A., Collins, N.E., 2010. Four p67 alleles identified in South African Theileria parva field samples. Vet. Parasitol. 167, 244-254.

Sibley, L.D., LeBlanc, A.J., Pfefferkorn, E.R., Boothroyd, J.C., 1992. Generation of a restriction fragment length polymorphism linkage map for Toxoplasma gondii. Genetics 132, 1003-1015.

Sivakumar, T., Altangerel, K., Igarashi, I., Xuan, X., Guo, G., Huang, X., Yokoyama, N., 2011. Phylogenetic analysis of Theileria orientalis in cattle bred in Fujian province, China. J. Protozool. Res. 21, 14-19.

Sivakumar, T., Tattiyapong, M., Fukushi, S., Kothalawala, H., Silva, S.S.P., Vimalakumar, S.C., Kanagaratnam, R., Meewewa, S.A., Suthaharan, K., Puvirajan, T., de Silva, W.K., Igarashi, I., Yokoyama, N., 2014. Genetic characterization of Babesia and Theileria parasites in water buffaloes in Sri Lanka. Vet. Parasitol. 200, 24-30.

Sivakumar, T., Yoshinari, T., Igarashi, I., Kothalawala, H., Abeyratne, A.S., Vimalakumar, S.C., Meewawe, A.S., Kuleswarakumar, K., Chandrasiri, A.D.N., Yokoyama, N., 2013. Genetic diversity within Theileria orientalis parasites detected in Sri Lankan cattle. Ticks Tick Borne Dis. 4, 235-241. 
Skilton, R.A., Musoke, A.J., Wells, C.W., Yagi, Y., Nene, V., Spooner, P.R., Gachanja, J., Osaso, J., Bishop, R.P., Morzaria, S.P., 2000. A 32 kDa surface antigen of Theileria parva: characterization and immunization studies. Parasitology 120, 553-564.

Stajich, J.E., Wilke, S.K., Ahrén, D., Au, C.H., Birren, B.W., Borodovsky, M., Burns, C., Canbäck, B., Casselton, L.A., Cheng, C.K., Deng, J., Dietrich, F.S., Fargo, D.C., Farman, M.L., Gathman, A.C., Goldberg, J., Guigó, R., Hoegger, P.J., Hooker, J.B., Huggins, A., James, T.Y., Kamada, T., Kilaru, S., Kodira, C., Kües, U., Kupfer, D., Kwan, H.S., Lomsadze, A., Li, W., Lilly, W.W., Ma, L.J., Mackey, A.J., Manning, G., Martin, F., Muraguchi, H., Natvig, D.O., Palmerini, H., Ramesh, M.A., Rehmeyer, C.J., Roe, B.A., Shenoy, N., Stanke, M., Ter-Hovhannisyan, V., Tunlid, A., Velagapudi, R., Vision, T.J., Zeng, Q., Zolan, M.E., Pukkila, P.J., 2010. Insights into evolution of multicellular fungi from the assembled chromosomes of the mushroom Coprinopsis cinerea (Coprinus cinereus). Proc. Natl. Acad. Sci. USA. 107, 11889-11894.

Steinaa, L., Saya, R., Awino, E., Toye, P., 2012. Cytotoxic T lymphocytes from cattle immunized against Theileria parva exhibit pronounced cross-reactivity among different strain-specific epitopes of the Tp1 antigen. Vet. Immunol. Immunopathol. 145, 571-581.

Su, X., Ferdig, M.T., Huang, Y., Huynh, C.Q., Liu, A., You, J., Wootton, J.C., Wellems, T.E., 1999. A genetic map and recombination parameters of the human malaria parasite Plasmodium falciparum. Science 286, 1351-1353. 
Sugimoto, C., Fujisaki, K., 2002. Non-transforming Theileria parasites of ruminants. In: Theileria. Dobbelaere, D. (Ed). Kluwer Academic publishers, Boston, pp. 93-105.

Swan, D.G., Phillips, K., Tait, A., Shiels, B.R., 1999. Evidence for localisation of a Theileria parasite AT hook DNA-binding protein to the nucleus of immortalised bovine host cells. Mol. Biochem. Parasitol. 101, 117-129.

Swan, D.G., Stern, R., McKellar, S., Phillips, K., Oura, C.A., Karagenc, T.I., Stadler, L., Shiels, B.R., 2001. Characterisation of a cluster of genes encoding Theileria annulata AT hook DNA-binding proteins and evidence for localisation to the host-cell nucleus. J. Cell. Sci. 114, 2747-2754.

Tamura, K., 1992. Estimation of the number of nucleotide substitutions when there are strong transition-transversion and G+C-content biases. Mol. Biol. Evol. 9, 678-687.

Tamura, K., Nei, M., 1993. Estimation of the number of nucleotide substitutions in the control region of mitochondrial DNA in humans and chimpanzees. Mol. Biol. Evol. 10, 512526.

Tamura, K., Peterson, D., Peterson, N., Stecher, G., Nei, M., Kumar, S., 2011. MEGA5: molecular evolutionary genetics analysis using maximum likelihood, evolutionary distance, and maximum parsimony methods. Mol. Biol. Evol. 28, 2731-2739. 
Tanriverdi, S., Blain, J.C., Deng, B., Ferdig, M.T., Widmer, G., 2007. Genetic crosses in the apicomplexan parasite Cryptosporidium parvum define recombination parameters. Mol. Microbiol. 63, 1432-1439.

Taracha, E.L., Goddeeris, B.M., Morzaria, S.P., Morrison, W.I., 1995a. Parasite strain specificity of precursor cytotoxic $\mathrm{T}$ cells in individual animals correlates with crossprotection in cattle challenged with Theileria parva. Infect. Immun. 63, 1258-1262.

Taracha, E.L., Goddeeris, B.M., Teale, A.J., Kemp, S.J., Morrison, W.I., 1995b. Parasite strain specificity of bovine cytotoxic $\mathrm{T}$ cell responses to Theileria parva is determined primarily by immunodominance. J Immunol. 155, 4854-4860.

Terada, Y., Ishida, M., Yamanaka, H., 1995. Resistibility to Theileria sergenti infection in Holstein and Japanese Black cattle. J. Vet. Med. Sci. 57, 1003-1006.

Toye, P.G., Goddeeris, B.M., Iams, K., Musoke, A.J., Morrison, W.I., 1991. Characterization of a polymorphic immunodominant molecule in sporozoites and schizonts of Theileria parva. Parasite Immunol. 13, 49-62.

Toye, P., Gobright, E., Nyanjui, J., Nene, V., Bishop, R., 1995. Structure and sequence variation of the genes encoding the polymorphic, immunodominant molecule (PIM), an antigen of Theileria parva recognized by inhibitory monoclonal antibodies. Mol. Biochem. Parasitol. 73, 165-177. 
Uilenberg, G., 1981. Theilerial species of domestic livestock, in: Irvin, A.D., Cunningham, M.P., Young, A.S. (Eds.), Advances in the Control of theileriosis: Proceedings of an international conference, held at the ILRAD, Nairobi, 9-13 February. Martinus Nijhoff., The Hague, pp. 4-37.

Uilenberg, G., 1999. Immunization against diseases caused by Theileria parva: a review. Trop. Med. Int. Health. 4, A12-20.

Uilenberg, G., Perié, N.M., Spanjer, A.A., Franssen, F.F., 1985. Theileria orientalis, a cosmopolitan blood parasite of cattle: demonstration of the schizont stage. Res. Vet. Sci. 38, $352-360$.

Walker-Jonah, A., Dolan, S.A., Gwadz, R.W., Panton, L.J., Wellems, T.E., 1992. An RFLP map of the Plasmodium falciparum genome, recombination rates and favored linkage groups in a genetic cross. Mol. Biochem. Parasitol. 51, 313-320.

Weir, W., Ben-Miled, L., Karagenç, T., Katzer, F., Darghouth, M., Shiels, B., Tait, A., 2007. Genetic exchange and sub-structuring in Theileria annulata populations. Mol. Biochem. Parasitol. 154, 170-180.

Weir, W., Karagenç, T., Baird, M., Tait, A., Shiels, B.R., 2010. Evolution and diversity of secretome genes in the apicomplexan parasite Theileria annulata. BMC Genomics 11, 42. 
Weir, W., Sunter, J., Chaussepied, M., Skilton, R., Tait, A., de Villiers, E.P., Bishop, R., Shiels, B., Langsley, G., 2009. Highly syntenic and yet divergent: a tale of two Theilerias. Infect. Genet. Evol. 9, 453-461.

Williamson, S., Tait, A., Brown, D., Walker, A., Beck, P., Shiels, B., Fletcher, J., Hall, R., 1989. Theileria annulata sporozoite surface antigen expressed in Escherichia coli elicits neutralizing antibody. Proc. Natl. Acad. Sci. 86, 4639-4643.

Whitehead, A., Crawford, D.L., 2006. Variation within and among species in gene expression: raw material for evolution. Mol. Ecol. 15, 1197-1211.

Yamaguchi, T., Yamanaka, M., Ikehara, S., Kida, K., Kuboki, N., Mizuno, D., Yokoyama, N., Narimatsu, H., Ikehara, Y., 2010. Generation of IFN-gamma-producing cells that recognize the major piroplasm surface protein in Theileria orientalis-infected bovines. Vet. Parasitol. 171, 207-215.

Yin, H., Luo, J., Schnittger, L., Lu, B., Beyer, D., Ma, M., Guan, G., Bai, Q., Lu, C., Ahmed, J., 2004. Phylogenetic analysis of Theileria species transmitted by Haemaphysalis qinghaiensis. Parasitol. Res. 92, 36-42.

Yokoyama, N., Sivakumar, T., Ota, N., Igarashi, I., Nakamura, Y., Yamashina, H., Matsui, S., Fukumoto, N., Hata, H., Kondo, S., Oshiro, M., Zakimi, S., Kuroda, Y., Kojima, N., Matsumoto, M., Inokuma, H., 2012. Genetic diversity of Theileria orientalis in tick vectors detected in Hokkaido and Okinawa, Japan. Infect. Genet. Evol. 12, 1669-1675. 
Yokoyama, N., Ueno, A., Mizuno, D., Kuboki, N., Khukhuu, A., Igarashi, I., Miyahara, T., Shiraishi, T., Kudo, R., Oshiro, M., Zakimi, S., Sugimoto, C., Matsumoto, K., Inokuma, H., 2011. Genotypic Diversity of Theileria orientalis Detected from Cattle Grazing in Kumamoto and Okinawa Prefectures of Japan. J. Vet. Med. Sci. 73, 305 -312.

Zweygarth, E., Koekemoer, O., Josemans, A.I., Rambritch, N., Pienaar, R., Putterill, J., Latif, A., Potgieter, F.T., 2009. Theileria-infected cell line from an African buffalo (Syncerus caffer). Parasitol. Res. 105, 579-581. 


\section{Figure legends}

Fig. 1. Phylogenetic analysis of $18 S$ rRNA gene sequences. Sequences were aligned using the online version of the MAFFT program (Katoh et al., 2002). The maximum likelihood phylogenetic tree was constructed by MEGA version 5.2 (Tamura et al., 2011), based on the Tamura-Nei substitution model (Tamura and Nei, 1993). Piroplasmids were classified into different groups as previously described (Criado-Fornelio et al., 2003). Archeopiroplasmids were considered to be the ancestors of piroplasmids. Theileria species of ruminants, which form a monophyletic clade with a high bootstrap value, are considered to be true Theileria. Note that the host-cell transforming parasites have a common ancestor and that the nontransforming parasites evolved without pronounced host specificity.

Fig. 2. Phylogenetic analysis of T. parva $p 67$ and its orthologous genes in T. taurotragi (STAG-1), T. annulata (SPAG-1), T. lestoquardi (SLAG-1), T. orientalis, T. equi, and Babesia bovis. Coding sequences were aligned using the online version of the MAFFT program (Katoh et al., 2002). The maximum likelihood phylogenetic tree was constructed using MEGA version 5.2 (Tamura et al., 2011), based on the Hasegawa-Kishino-Yano substitution model (Hasegawa et al., 1985). Note that the host-cell transforming parasites have a common ancestor and that $T$. taurotragi is closely related to $T$. parva.

Fig. 3. Phylogenetic analysis of T. orientalis MPSP gene sequences. After multiple alignment using the online version of the MAFFT program (Katoh et al., 2002), the maximum likelihood phylogenetic tree was constructed using MEGA version 5.2 (Tamura et al., 2011) based on the Tamura 3-parameter substitution model (Tamura, 1992). Note that the MPSP sequences can be classified into 11 allelic types. 
Fig. 4. The geographical distribution of T. orientalis MPSP-types reported in different host species. The numbers 1-8 and N1, N2, and N3 in the circles represent the respective MPSPtypes. The colors of the circles indicate the different host species, as shown in the figure. Note that the distributions of T. orientalis MPSP-types detected in cattle, water buffaloes, yaks, and sheep differ among the various countries. 
Table 1 Recombination rates in various species

\begin{tabular}{lll}
\hline Organism & Reference & Recombination rate (kb/cM $)^{\mathrm{a}}$ \\
\hline T. parva & Katzer et al., 2011 & 4.6 \\
P. falciparum & Jiang et al., 2011 & 12.8 \\
& $\begin{array}{l}\text { Su et al., 1999 } \\
\text { Walker-Jonah et al., 1992 }\end{array}$ & 17 \\
& Martinelli et al., 2005 & $15-30$ \\
P. chabaudi & Khan et al., 2005 & 13.7 \\
T. gondii & Sibley et al., 1992 & 104 \\
& Tanriverdi et al., 2007 & $120-300$ \\
C. parvum & Stajich et al., 2010 & $10-56$ \\
Coprinopsis cinerea & Jensen-Seaman et al., 2004 & 33 \\
Human & Jensen-Seaman et al., 2004 & 795.6 \\
Rat & Jensen-Seaman et al., 2004 & 1656.1 \\
Mouse &
\end{tabular}

${ }^{a}$ Lower values suggest higher recombination efficiency. 
T. sergenti, Cattle (AF081137)

100 T. buffeli, Cattle (AF236097)

37 T. orientalis, Cattle (HM538222)

T. sinensis, Yak (EU274472)

21 Theileria. sp., Japanese serow (AB602880)

58 Theileria. sp., Japanese serow (AB602881)

T. luwenshuni, Small ruminant (JX469518)

Theileria. sp., Chinese water deer (GQ292535)

12 -Theileria. sp., Gray duiker (AY748466)

Theileria. sp., Common tsessebe (HQ179765)

99 -T. separata, Sheep (AY260175)

16 LTheileria. sp., Dama gazelle (AY735116)

Theileria. sp., Sika deer (AB602887)

Theileria. sp., Sika deer (AF529272)

23

T. capreoli, European roe deer (AY726011)

T. ovis, Sheep (AY260171)

Theileria. sp., Giraffe (FJ213582)

Theileria. sp., Giraffe (FJ213583)

Theileria. sp., Giraffe (JQ928928)

T. velifera, Cattle (AF097993)

100

-T. cervi, Elk (AY735130)

TT. uilenbergi, Sheep (JF719835)

T. mutans, Cattle (AF078815)

Theileria. sp., White-tailed deer (AY735131)

Theileria. sp., Reindeer (JN086222)

61

T. annulata, Cattle (EU083799)

78 T. lestoquardi, Sheep (AF081135)

T. taurotragi, Cattle (L19082)

T. parva, Cattle (L02366)

Theileria sp. (buffalo), African buffalo (HQ895982)

T. equi, Horse (HM229408)

T. youngi, Dusky-footed woodrat (AF245279)

70

Cytauxzoon felis, Cat (L19080)

-T. bicornis, Black rhinoceruos (AF499604)

$B$ bigemina, Cattle (X59604)

B. bovis, Cattle (M87566)

Theilerids

99 B. caballi, Horse (Z15104)

B. divergens, Cattle (Z48751)

B. gibsoni, Dog (AF175300)

79 - B. canis, Dog (AY072926)

$100-$ B. gibsoni, Dog (AF231350)

Babesia sp., Human (AY027816)

Prototheilerids

64

B. microti, Rodent (U09833)

'T. annae, Dog (AF188001)

100 B. rodhaini, Small mammals (M87565)

Archaeopiroplasmids

B. leo, Lion (AF244911)

B. felis, Cat (AF244912)

Babesids

Ungulibabesids

$100-$ Cardiosporidium cionae, Ascidian (EU052685)

100 Nephromyces sp., Sea grapes (HM469384)

Marine parasites

Lephromyces sp., Sea grapes (HM469382)

P. falciparum, Human (M19172) 


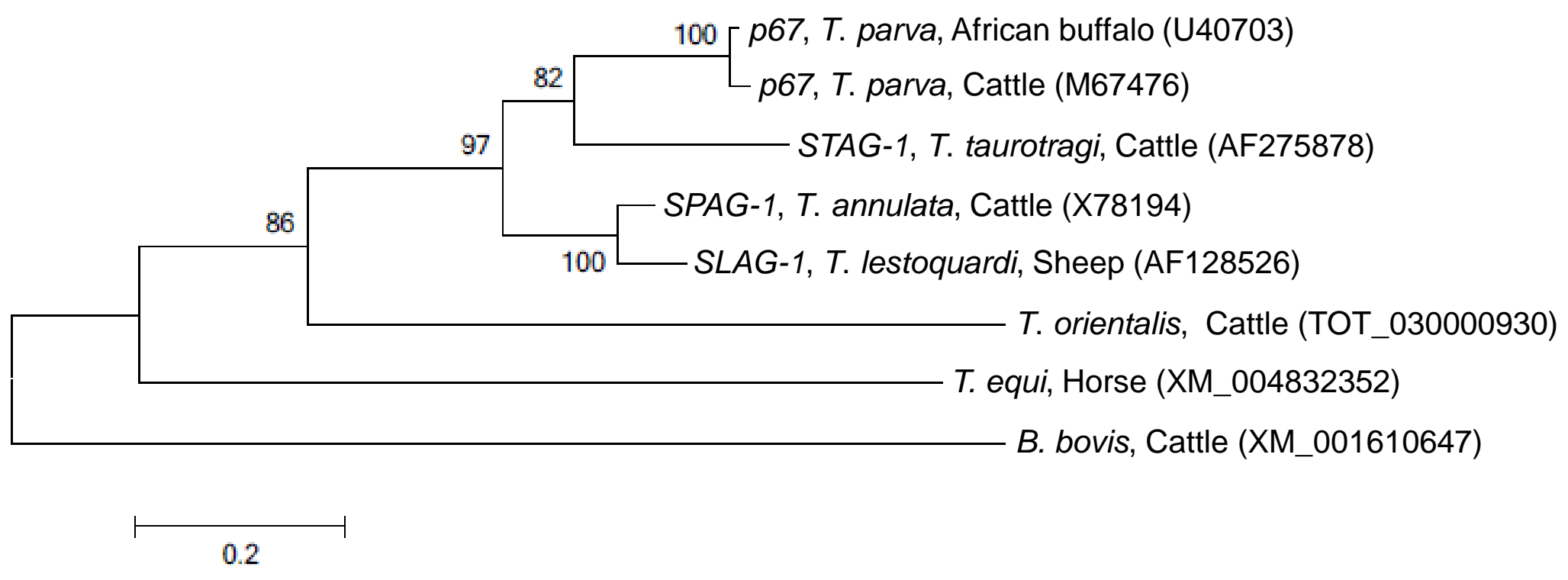

Fig. 2. Sivakumar et al. 


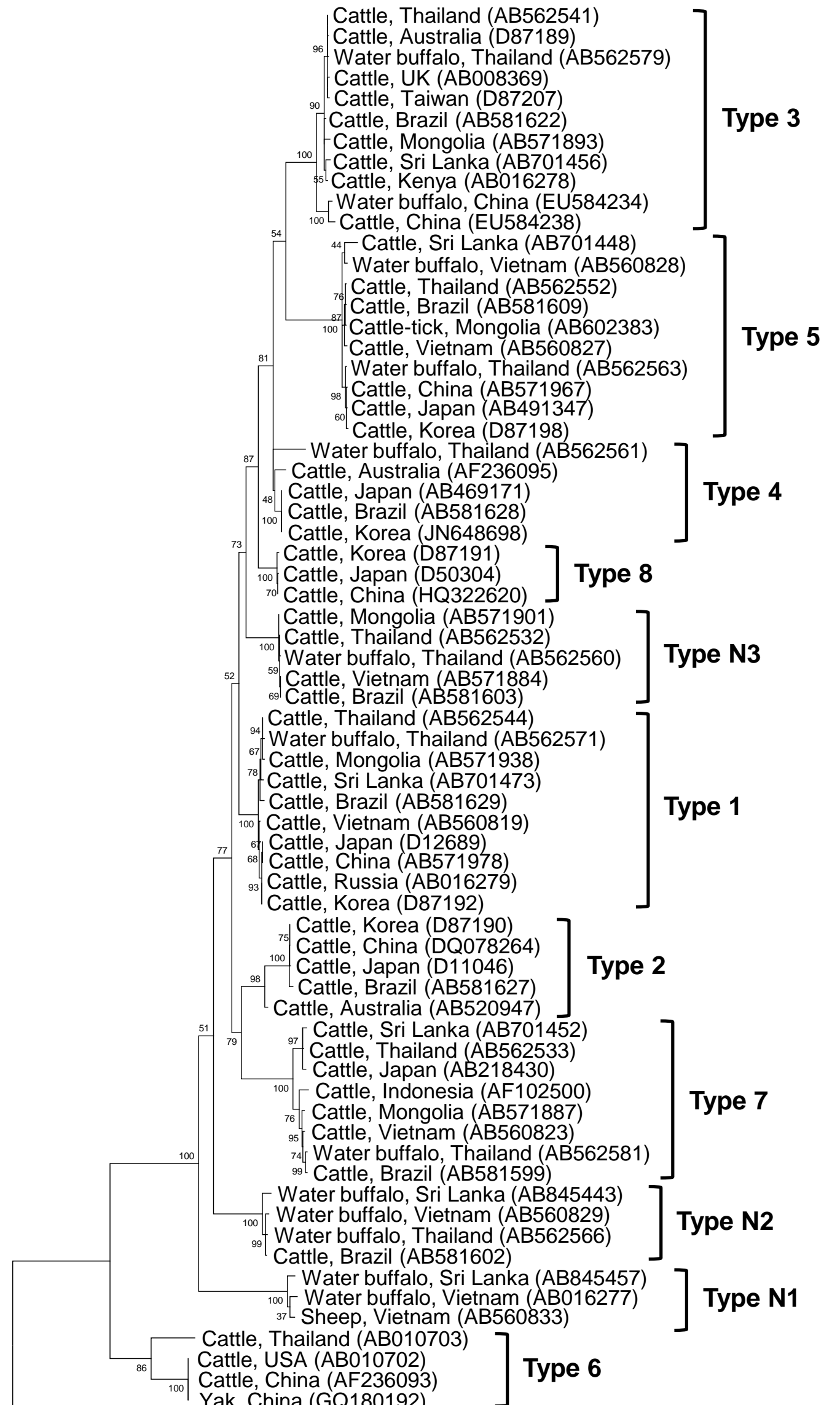



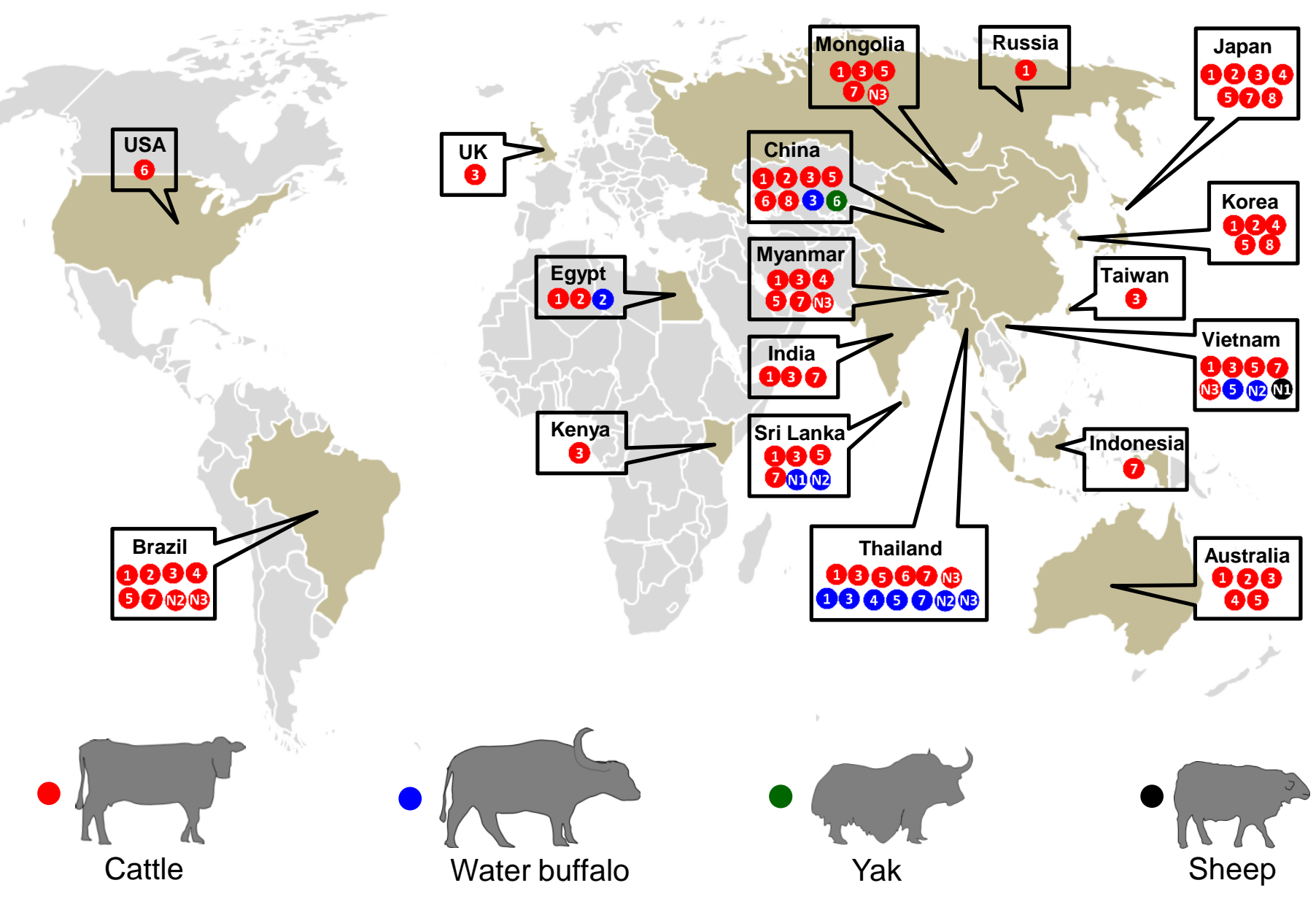

Fig. 4. Sivakumar et al. 